\title{
The Responses of Wages and Prices to Technology Shocks*
}

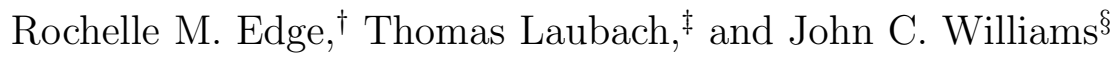

December 10, 2003

\begin{abstract}
This paper reexamines wage and price dynamics in response to permanent shocks to productivity. We estimate a micro-founded dynamic general equilibrium (DGE) model of the U.S. economy with sticky wages and sticky prices using impulse responses to technology and monetary policy shocks. We utilize a flexible specification for wageand price-setting that allows for the sluggish adjustment of both the levels of these variables - as in standard contracting models - as well as intrinsic inertia in wage and price inflation. On the price front, we find that in our VAR inflation jumps in response to an identified permanent technology shock, implying that, on average, prices adjust quickly and that there is little evidence for any intrinsic inflation inertia like that commonly found in models used for monetary policy evaluation. On the wage front, we find evidence for significant inertia in wages and some intrinsic inertia in nominal wage inflation. Our results provide support for the standard sticky-price specification of the New Keynesian model; however, the evidence on the high degree of wage inertia presents a challenge for standard models of wage setting.
\end{abstract}

Keywords: Inflation interia, Estimated DGE models.

JEL classification: E24, E31, 040.

${ }^{*}$ We thank Michael Dotsey, Andreas Hornstein, Eric Leeper, Ed Nelson, Argia Sbordone, Stephanie Schmitt-Grohe, and Michael Woodford, as well as participants at the 2003 AEA, SED, and SCE Meetings, the Spring 2003 Federal Reserve Macroeconomics System Committee Meetings, the Sveriges Riksbank Conference on Small Structural Models for Monetary Policy Analysis, the Rutgers University macroeconomics workshop, and the Federal Reserve Board lunchtime workshop, for helpful comments on this research project and paper. The views expressed here are those of the authors and do not necessarily reflect the views of the Board of Governors of the Federal Reserve System or its staff, the management of the Federal Reserve Bank of San Francisco, or the OECD.

${ }^{\dagger}$ Federal Reserve Board, rochelle.m.edge@frb.gov.

${ }^{\ddagger}$ Federal Reserve Board and OECD, thomas.laubach@oecd.org. (Corresponding author.)

${ }^{\S}$ Federal Reserve Bank of San Francisco, john.c.williams@sf.frb.org. 


\section{Introduction}

The nature of price inertia has important implications for the design and conduct of monetary policy, and so it is unsurprising that recent years have seen a resurgence in theoretical and empirical research aiming to disentangle the sources of sluggishness in wages and prices. The focus of this literature has been in two main areas. First, as documented by Fuhrer and Moore (1995), standard sticky-price theories (such as those formulated by Calvo, 1983, Taylor, 1980, and Rotemberg, 1982), cannot explain the high degree of persistence in postwar U.S. inflation data, absent of serially correlated shocks to inflation. As a result, much of the subsequent monetary policy literature - for example, Fuhrer (1997a), Levin, Weiland, and Williams (2003), and Rudebusch (2002) - has assumed some form of intrinsic inflation inertia. Second, Galí and Gertler (1999) have argued that simple inflation models, where inflation depends on its own leads and lags and a measure of the output gap are misspecified, and have emphasized the role of marginal cost in determining inflation. This paper reexamines price and wage dynamics in an optimization-based dynamic general equilibrium framework in which we explicitly model the joint determination of wages and prices. We allow for a general form of intrinsic inertia in both wages and prices that nests standard sticky-wage and sticky-price formulations as well as full-indexation models such as those of Fuhrer and Moore (1995) and Christiano, Eichenbaum, and Evans (2003).

Our empirical approach relies primarily on the properties of inflation following a permanent shock to productivity that directly affects marginal costs. As discussed below, the moments of the data conditional on a productivity shock are arguably less contaminated by misspecification than other unconditional or conditional moments. Following Galí (1999) and Altig, Christiano, Eichenbaum, and Linde (2002), we measure the effects of such a shock using an identified technology innovation in an estimated VAR. We then estimate the structural parameters of an optimization-based model of the U.S. economy based on matching the impulse responses to shocks to technology and monetary policy, following the methodology of Rotemberg and Woodford (1997) and Christiano et al. (2003).

A technology shock directly affects marginal costs, making it an exceptionally "clean" experiment to evaluate the behavior of prices and wages. In particular, misspecification of monetary policy, emphasized by Erceg and Levin (2003) as a source of bias in estimates of inflation inertia, should have a relatively small effect on the estimated short-term reaction of inflation to the shock. In contrast, a shock to monetary policy or some other macroeco- 
nomic relationship primarily affects inflation indirectly through the effects of the shock on expectations of output and marginal costs. As such, estimates of the effects of such shocks generated by the VAR rely crucially on the correct specification of monetary policy and other relationships in the VAR. Given the evidence for significant shifts in the conduct of monetary policy over the past four decades, such an assumption seems questionable at best.

Analysis of the impulse responses to the technology shock yields two key findings related to price- and wage-setting. First, according to our estimated VAR, prices adjust very quickly in response to an identified shock to productivity: Price inflation drops immediately after the onset of the shock and returns to steady state in two years. In the context of our model, this price inflation response implies that prices adjust relatively frequently, consistent with survey evidence. Moreover, it implies the absence of intrinsic inflation inertia. A significant degree of inflation inertia would counterfactually predict that the response of inflation would initially be muted, and then follow a hump shape. Thus, conditional on the response of marginal costs, the standard sticky-price model without inflation inertia is sufficient to explain the impulse response to a technology shock.

In contrast to prices, we find a high degree of inertia in nominal wages. Absent of sticky wages, our model is unable to replicate the dynamic responses to the technology shock implied by the VAR, a finding previously empasized by Altig et al. (2002). In particular, the sluggishness in nominal wages is needed to explain the gradual adjustment of the real wage to its higher steady-state level following an increase in productivity seen in the VAR impulse response. The estimated high degree of wage inertia, however, is difficult to reconcile with the direct evidence on wage contracts and other evidence based on standard theories of wage determination, which both suggest more rapid adjustment of wages. Our model point estimates also imply some inertia in the growth rate of nominal wage inflation, but quantitatively the effect of this intrinsic inertia in wage growth on the model has modest importance. Thus, our findings support the approachs of Erceg, Henderson, and Levin (2000), Amato and Laubach (2003), and Christiano, Eichenbaum, and Evans (2003), that sticky wages represent an essential building block in an empirical dynamic general equilibrium model, but leave unanswered the question as to why wages appear to be so sluggish.

The paper is organized as follows. Section 2 outlines the technology and preferences underlying our model. Section 3 describes the decentralization of the economy and the 
equilibrium conditions. Section 4 presents the estimation methodology and results. Section 5 considers the issue of wage and price-setting in more detail. Section 6 concludes.

\section{Technology and Preferences}

In this section, we describe the technology and preferences describing our model. This model shares many features with those developed by Fuhrer (1997b), Christiano, Eichenbaum, and Evans (2003), Smets and Wouters (2002), and Altig, Christiano, Eichenbaum, and Linde (2002). Importantly, the dynamics of nominal and real variables are determined by first-order conditions of optimizing agents. In order for the model to fit the data reasonably well, we allow for various frictions such as habit formation and adjustment costs that interfere with instantaneous full adjustment in response to shocks. ${ }^{1}$ As in Altig et al. (2002), ours is a two-sector model in which the level and growth rates of technology are allowed to differ across the consumption and investment goods sectors. In the next section we turn to the decentralization of this economy and derive the conditions describing the decentralized equilibrium.

\subsection{The Production Technology}

Two distinct final goods are produced: consumption goods (denoted $Y_{c, t}$ ) and investment goods (denoted $Y_{i, t}$ ). Given the current levels of technology in each final goods sector denoted by $A_{s, t}$ for sector $s$, consumption and investment goods are produced by aggregatingaccording to a Dixit-Stiglitz technology — an infinite number of differentiated intermediate material goods. Specifically, final goods production in sector $s$ in period $t$ is represented by the function

$$
Y_{s, t}=A_{s, t}^{1-\alpha}\left(\int_{0}^{1} Y_{m, s, t}(x)^{\frac{\theta-1}{\theta}} d x\right)^{\frac{\theta}{\theta-1}}, s=c, i,
$$

where the variable $Y_{m, s, t}(x)$ denotes the quantity of the intermediate materials good indexed by type $x \in[0,1]$ used to produce final output in sector $s$ and $\theta$ is the elasticity of substitution between the differentiated materials inputs used in the production, assumed to be the same in both sectors.

\footnotetext{
${ }^{1}$ Estrella and Fuhrer (2002) document the shortcomings of optimization-based models that do not incorporate such sources inertia.
} 
The differentiated intermediate materials goods used as inputs in equation (1) are themselves produced by combining each variety of our economy's differentiated labor inputs $\left\{L_{t}(x)\right\}, x \in[0,1]$ with physical capital $K_{t}$. Capital can be utilized at varying intensities, denoted by $U_{t} \geq 0$. A Dixit-Stiglitz aggregator characterizes the way in which differentiated labor inputs are used together in the production of the economy's materials goods, while a Cobb-Douglas production function then characterizes how the composite bundle of labor, denoted $L_{t}$, is combined with utilized capital to produce, given the current level of technology $A_{m, t}$, output of intermediate materials goods. The production of materials good $z$, for $z \in[0,1]$, is determined by:

$$
\begin{gathered}
Y_{m, t}(z)=\left(K_{t}(z) U_{t}(z)\right)^{\alpha}\left(A_{m, t} L_{t}(z)\right)^{1-\alpha}-K_{t}(z) \Psi\left(U_{t}(z)\right)\left(A_{i, t}\right)^{-(1-\alpha)} \\
\text { where } L_{t}(z)=\left(\int_{0}^{1} L_{t}(x, z)^{\frac{\rho-1}{\rho}} d x\right)^{\frac{\rho}{\rho-1}}
\end{gathered}
$$

where we assume that $\Psi(1) \geq 0, \Psi^{\prime}(1) \geq 0$, and $\Psi^{\prime \prime}(1) \geq 0$. The parameter $\alpha$ denotes the elasticity of output with respect to capital, while $\rho$ denotes the elasticity of substitution between the differentiated labor inputs.

The log-level of technology in each of the three sectors $(s=c, i, m)$ is modeled as a random walk with drift:

$$
\ln A_{s, t}=\ln \Gamma_{a, s}+\ln A_{s, t-1}+\epsilon_{s, t}, s=c, i, m
$$

where $\epsilon_{s, t}$ is an i.i.d. innovation, and $\Gamma_{a, s}$ is the constant trend growth rate of technology in sector $s$. Note that in this paper we restrict ourselves to permanent shocks to the level of technology, focusing on economy-wide shocks to total factor productivity. Economy-wide (or sector-neutral) productivity shocks are implemented through an innovation to technology in the intermediate materials good sector. In a companion paper, Edge, Laubach, and Williams (2003), we consider sector-specific shocks to technology and shifts in the growth rate of technology.

\section{$2.2 \quad$ The Capital Evolution Technology}

The law of motion for the economy's beginning of period $t+1$ capital stock $K_{t+1}$ is given by:

$$
K_{t+1}=(1-\delta) K_{t}+I_{t} \exp \left[-\frac{\chi_{i}}{2}\left(\frac{I_{t}}{I_{t-1}}-\Gamma_{i}\right)^{2}\right]
$$


where $I_{t}$ is gross investment, $\delta$ is the depreciation rate, and $\Gamma_{i}$ is the steady-state growth rate of investment. The final term multiplying $I_{t}$ measures the fraction of investment that contributes to the capital stock after adjustment costs. The fraction of investment lost to adjustment costs is zero when investment growth, $I_{t} / I_{t-1}$, equals the trend rate of growth of technology in the investment goods sector, but rises to above zero, at an increasing rate, as investment growth moves further away from its trend. The parameter $\chi_{i} \geq 0$ governs how quickly adjustment costs increase as investment growth moves away from $\Gamma_{i}$. The economy's resource constraint implies that $I_{t} \leq Y_{i, t}$.

\subsection{Preferences}

Households derive utility from their purchases of the consumption good $C_{t}$ and from their use of leisure time, equal to what remains of their time endowment $\bar{L}$ after $0 \leq L_{t}(i) \leq \bar{L}$ hours of labor are supplied to market activities. The preferences of household $i \in[0,1]$ over consumption and leisure are nonseparable, with household $i$ 's consumption habit stock (assumed to equal a fraction $\eta \in[0,1]$ of its consumption last period) influencing the utility it derives from current consumption. Note that we assume that utility is nonseperable between consumption and leisure, consistent with evidence of Basu and Kimball (2002). Specifically, preferences of household $i$ are given by

$$
E_{0} \frac{1}{1-\sigma} \sum_{t=0}^{\infty} \beta^{t}\left[\left(C_{t}(i)-\eta C_{t-1}(i)\right)\left(\bar{L}-L_{t}(i)\right)^{\zeta}\right]^{1-\sigma},
$$

where $\beta$ is the household's discount factor, and $\zeta$ is a measure of the utility of leisure. The economy's resource constraint implies that $\int_{0}^{1} C_{t}(x) d x \leq Y_{c, t}$.

\section{The Decentralized Economy}

We now discuss the agents of our economy and their respective optimization problems. We assume the following decentralization. There is one representative, perfectly competitive firm in each of the two final-goods producing sectors, which purchases intermediate inputs from the continuum of materials goods producers. The materials goods producers, in turn, rent capital from a perfectly competitive representative capitalist, and differentiated types of labor from households. The capitalist purchases the investment good from

the investment-goods producing firm, and households purchase the consumption good from 
the consumption-goods producing firm. Because both materials goods producers and households are monopolistic competitors, they also set prices at which they supply their respective products or labor services.

\subsection{Final Goods Producers}

The competitive firm in the consumption good sector owns the production technology described in equation (1) for $s=c$, while the competitive firm in the capital goods sector owns the same technology for $s=i$. Each final-good producing firm, taking as given the prices set by each intermediate-good producer for their differentiated output, that is $\left\{P_{m, t}(j)\right\}_{j=0}^{1}$, chooses intermediate inputs $\left\{Y_{m, s, t}(j)\right\}_{j=0}^{1}$ so as to minimize the cost of producing its final output $Y_{s, t}$, subject its production technology, given by equation (1). Specifically, the competitive firm in each sector solves

$$
\min _{\left\{Y_{m, s, t}(j)\right\}_{j=0}^{1}=0} \int_{0}^{1} P_{t}(x) Y_{m, s, t}(x) d x \text { s.t. } Y_{s, t} \leq A_{s, t}^{1-\alpha}\left(\int_{0}^{1} Y_{m, s, t}(x)^{\frac{\theta-1}{\theta}} d x\right)^{\frac{\theta}{\theta-1}}, s=c, i .
$$

The cost-minimization problems solved by firms in the economy's consumption and capital goods producing sectors imply economy-wide demand functions for each intermediate good that are given by

$$
Y_{m, t}(j)=\left(\frac{P_{m, t}(j)}{P_{m, t}}\right)^{-\theta} \sum_{s=c, i} \frac{Y_{s, t}}{A_{s, t}^{1-\alpha}} .
$$

The variable $P_{m, t}$ denotes the aggregate price level in the intermediate goods sector and is defined by $P_{m, t}=\left(\int_{0}^{1}\left(P_{m, t}(x)\right)^{1-\theta} d x\right)^{\frac{1}{1-\theta}}$. The cost-minimization problems solved in each final-good producing sector imply that the competitive price for consumption and investment goods, respectively, are given by $P_{c, t}=P_{m, t} A_{c, t}^{-(1-\alpha)}$ and $P_{i, t}=P_{m, t} A_{i, t}^{-(1-\alpha)}$.

\subsection{Intermediate Goods Producers}

Each intermediate (or materials) good producing firm $j \in[0,1]$ owns the production technology described in equations (2) and (3). In considering firm $j$ 's problem-of choosing the quantities of differentiated labor services $\left\{L_{t}(i, j)\right\}_{i=0}^{1}$, capital $K_{t}(j)$, and the degree of utilization $U_{t}(j)$ that it will use in production - it is convenient to split the decision into two separate stages. In the first step of the problem firm $j$, taking as given the wages $\left\{W_{t}(i)\right\}_{i=0}^{1}$ set by each household for its variety of labor, chooses $\left\{L_{t}(i, j)\right\}_{i=0}^{1}$ to minimize the cost of attaining the aggregate labor bundle $L_{t}(j)$ that it will ultimately need for 
production. Specifically, the materials firm $j$ solves:

$$
\min _{\left\{L_{t}(i, j)\right\}_{i=0}^{1}} \int_{0}^{1} W_{t}(x) L_{t}(x, j) d x \text { s.t. } L_{t}(j) \leq\left(\int_{0}^{1} L_{t}(x, j)^{\frac{\rho-1}{\rho}} d x\right)^{\frac{\rho}{\rho-1}}
$$

The cost-minimization problem undertaken by each materials producing firm implies that the economy-wide demand for type $i$ labor is

$$
L_{t}(i)=\int_{0}^{1} L_{t}(i, x) d x=\left(\frac{W_{t}(i)}{W_{t}}\right)^{-\rho} \int_{0}^{1} L_{t}(x) d x
$$

where $W_{t}$ denotes the aggregate wage, defined by $W_{t}=\left(\int_{0}^{1}\left(W_{t}(x)\right)^{1-\rho} d x\right)^{\frac{1}{1-\rho}}$. In the second step of the problem firm $j$, taking as given the aggregate wage $W_{t}$ and the rental rate on capital $R_{k, t}$, chooses aggregate labor $L_{t}(j)$, capital $K_{t}(j)$, and utilization $U_{t}(j)$ to minimize the costs of attaining its desired level of output $Y_{m, t}(j)$. Specifically, the firm solves

$$
\begin{aligned}
\min _{K_{t}(j), L_{t}(j), U_{t}(j)} & R_{k, t} K_{t}(j)+W_{t} L_{t}(j) \\
& \text { s.t. } Y_{m, t}(j) \leq\left(K_{t}(j) U_{t}(j)\right)^{\alpha}\left(A_{m, t} L_{t}(j)\right)^{1-\alpha}-K_{t}(j) \Psi\left(U_{t}(j)\right)\left(A_{i, t}\right)^{-(1-\alpha)}
\end{aligned}
$$

Since each firm produces its own differentiated variety of materials output $Y_{m, t}(j)$, it is able to set its price $P_{m, t}(j)$, which it does taking into account the demand schedule for its output that it faces from the consumption and capital goods sectors (equation 8). Intermediate materials goods-producing firms are assumed to face non-negative adjustment costs in altering both the level and the rate of change in their prices. For this purpose, we apply the generalized adjustment cost model due to Tinsley (1993) and discussed in Kozicki and Tinsley (1999). We prefer this approach over that of common alternatives because the latter imply heterogeneity among agents. Partly for this reason, models utilizing staggered price and wage setting typically assume that utility is separable between consumption and leisure, in which case perfect insurance among households against labor income risk eliminates heterogeneity of their spending decisions. By contrast, if wages are staggered and household utility is nonseparable, differences across households in labor supply (which will result due to differences in wages set) lead to differences across household in the marginal utility of consumption (and hence consumption), even if perfect insurance is able to equalize wealth across households. The quadratic adjustment cost model allows us to avoid heterogeneity across agents. In any case, the resulting price and wage inflation equations are very similar to those derived from Calvo-based setups with inertia as in Christiano, Eichenbaum, and Evans (2003) and Smets and Wouters (2002). 
The price adjustment costs (denote by $\chi_{p, 1}$ and $\chi_{p, 2}$, respectively) appear as an expense against firms' profits and are thus factored into their profit-maximization problem. The intermediate-good producing firm $j$, taking as given the marginal cost $M C_{m, t}(j)$ for producing $Y_{m, t}(j)$, the aggregate material price level $P_{m, t}$, and aggregate materials output $Y_{m, t}$, chooses its price $P_{m, t}(j)$ to maximize the present discounted value of its profits subject to the demand curve it faces for its differentiated output (equation 8). The materials producer's profit-maximization problem is given by

$$
\begin{gathered}
\max _{\left\{P_{m, t}(j)\right\}_{t=0}^{\infty}} E_{0} \sum_{t=0}^{\infty} \beta \frac{\Lambda_{c, t}}{P_{c, t}}\left\{\left(P_{m, t}(j)-M C_{m, t}(j)\right) Y_{m, t}(j)\right. \\
\left.-\left[\frac{\chi_{p, 1}}{2}\left(\Pi_{m, t}(j)-\bar{\Pi}_{m}\right)^{2}+\frac{\chi_{p, 2}}{2}\left(\frac{\Pi_{m, t}(j)}{\Pi_{m, t-1}(j)}-1\right)^{2}\right] P_{m, t} Y_{m, t}\right\} \\
\text { s.t. } Y_{m, t}(j)=\left(\frac{P_{m, t}(j)}{P_{m, t}}\right)^{-\theta}\left(\frac{Y_{c, t}}{A_{c, t}^{1-\alpha}}+\frac{Y_{i, t}}{A_{i, t}^{1-\alpha}}\right),
\end{gathered}
$$

where the discount factor that is relevant when comparing nominal revenues and costs in period $t$ with those in period $t+j$ is $E_{t} \beta^{j} \frac{\Lambda_{c, t+j} / P_{c, t+j}}{\Lambda_{c, t} / P_{c, t}}$, where $\Lambda_{c, t}$ is the household's marginal utility of consumption in period $t$. The parameter $\bar{\Pi}_{m}$ is the steady-state rate of aggregate materials price inflation.

\subsection{Capitalists}

The capitalist possesses the technology described in equation (5) for transforming capital goods, purchased from capital goods producers, into capital that can be rented and used productively by materials firms. The competitive capitalist, taking as given the rental rate on capital $R_{k, t}$, the price of investment goods $P_{i, t}$, and the stochastic discount factor chooses investment to maximize the present discounted value of profits subject to the law of motion governing the evolution of capital (equation 5$).^{2}$ Specifically, the capitalist solves:

$$
\max _{\left\{I_{t}, K_{t+1}\right\}_{t=0}^{\infty}} E_{0} \sum_{t=0}^{\infty} \beta \frac{{ }^{t} \Lambda_{c, t}}{P_{c, t}}\left[R_{k, t} K_{t}-P_{i, t} I_{t}\right] \text { s.t. } K_{t+1} \leq(1-\delta) K_{t}+I_{t} \exp \left[-\frac{\chi_{i}}{2}\left(\frac{I_{t}}{I_{t-1}}-\Gamma_{k}\right)^{2}\right] .
$$

\footnotetext{
${ }^{2}$ The economy's capital stock is also ultimately owned by the households, so that the relevant discount factor in comparing nominal earnings and expenditures in period $t$ with those in period $t+j$ is $\beta^{j} \frac{\Lambda_{c, t+j} / P_{c, t+j}}{\Lambda_{c, t} / P_{c, t}}$.
} 


\subsection{Households}

The representative household's utility, which is defined over consumption and leisure, is described by equation (6). Since each household supplies its own differentiated variety of labor $L_{t}(i)$, it is able to set its wage $W_{t}(i)$ subject to the labor demand schedule that it faces from the materials producing sector (equation 10). Analogous to materials producers, the household faces non-negative adjustment costs (denoted by $\chi_{w, 1}$ and $\chi_{w, 2}$ ) in terms of altering both the level and growth rate of its nominal wage. These adjustment costs appear as an expense against income in the household's budget constraint and are thus factored into the household's utility-maximization problem. The household's budget constraint with costly wage adjustment is is given by

$$
\begin{aligned}
E_{t}\left[\beta \frac{\Lambda_{c, t+1} / P_{c, t+1}}{\Lambda_{c, t} / P_{c, t}} B_{t+1}(i)\right] & =B_{t}(i)+W_{t}(i) L_{t}(i)+\text { Profits }_{t}(i)-P_{c, t} C_{t}(i) \\
& -\left[\frac{\chi_{w, 1}}{2}\left(\Pi_{w, t}(i)-\bar{\Pi}_{w}\right)^{2}-\frac{\chi_{w, 2}}{2}\left(\frac{\Pi_{w, t}(i)}{\Pi_{w, t-1}(i)}-1\right)^{2}\right] P_{c, t} C_{t},
\end{aligned}
$$

where the variable $B_{t}(i)$ is the state-contingent value, in terms of the numeraire, of household $i$ 's asset holdings at the beginning of period $t$. We assume that there exists a risk-free oneperiod bond, which pays one unit of the numeraire in each state, and denote its yield - that is, the gross nominal interest rate between periods $t$ and $t+1$-by $R_{t} \equiv\left(E_{t} \beta \frac{\Lambda_{c, t+1} / P_{c, t+1}}{\Lambda_{c, t} / P_{c, t}}\right)^{-1}$. Profits are those repatriated from capitalist and materials producing firms who, as already noted, are ultimately owned by households. The parameter $\bar{\Pi}_{w}$ is the steady-state rate of aggregate nominal wage inflation.

The household takes as given the expected path of the gross nominal interest rate $R_{t}$, the consumption good price level $P_{c, t}$, the aggregate wage rate $W_{t}$, profits income, and the initial bond stock $B_{i, 0}$, and chooses its consumption $C_{t}(i)$ and its wage $W_{t}(i)$ to maximize its utility subject to its budget constraint and the demand curve it faces for its differentiated labor. Specifically, the household solves:

$$
\begin{gathered}
\max _{\left\{C_{t}(i), W_{t}(i)\right\}_{t=0}^{\infty}} E_{0} \sum_{t=0}^{\infty} \beta^{t} \frac{\left[\left(C_{t}(i)-\eta C_{t-1}(i)\right)\left(\bar{L}-L_{t}(i)\right)^{\zeta}\right]^{1-\sigma}}{1-\sigma} \\
\text { s.t. equation (14) and } L_{t}(i)=\left(\frac{W_{t}(i)}{W_{t}}\right)^{-\rho} \int_{0}^{1} L_{t}(j) d j .
\end{gathered}
$$




\subsection{Monetary Authority}

In the spirit of the literature on monetary policy feedback reaction functions, we assume that the central bank uses the short-term interest rate as its instrument. This rate is determined in accordance with an interest rate feedback equation by which the short-term interest rate responds to deviations of inflation and economy-wide capacity utilization from their respective steady-state levels. ${ }^{3}$ We also allow for policy inertia by including the lagged short-term interest rate in the feedback equation. In particular, monetary policy is described by

$$
r_{t}=\phi_{r} r_{t-1}+\phi_{\pi}\left(\Pi_{m, t}-1\right)+\phi_{u} \ln U_{t}+\epsilon_{r, t},
$$

where $r_{t}$ denotes the short-term interest rate (equal to $R_{t}-1$ ), $U_{t}$ denotes economy-wide capacity utilization (equal to $\int_{0}^{1} U_{t}(x) d x$ ) and $\epsilon_{r, t}$ is an i.i.d. policy shock. Note that we have suppressed the constant that incorporates the steady-state levels of the interest rate, inflation rate, and capacity utilization rate.

\subsection{Equilibrium}

The decentralized equilibrium is an allocation:

$\left\{\left\{Y_{m, t}\right\}_{i=0}^{1}, Y_{m, t}, Y_{c, t}, Y_{i, t},\left\{C_{t}(i)\right\}_{i=0}^{1},\left\{L_{t}(i)\right\}_{i=0}^{1}, I_{t}, K_{t+1},\left\{K_{t}(j)\right\}_{j=0}^{1},\left\{\left\{L_{t}(i, j)\right\}_{i=0}^{1}\right\}_{j=0}^{1}, U_{t},\left\{U_{t}(j)\right\}_{j=0}^{1}\right\}_{t=0}^{\infty}$

and sequences of prices:

$$
\left\{\Pi_{m, t}, \Pi_{c, t}, \Pi_{i, t}, \Pi_{w, t},\left\{P_{m, t}(i)\right\}_{j=0}^{1}, P_{c, t}, P_{i, t}, Q_{k, t}, R_{k, t},\left\{W_{t}(i)\right\}_{i=0}^{1},\left\{M C_{m, t}(j)\right\}_{j=0}^{1}, R_{t}\right\}_{t=0}^{\infty}
$$

that satisfy the following conditions:

- final-good producing firms solve (7) for $s=c$ and $i$;

- all materials producers $j \in[0,1]$ solve (9), (11), and (12);

- the capitalist solves (13);

- all households $i \in[0,1]$ solve (15);

- the monetary authority follows (16);

\footnotetext{
${ }^{3}$ Capacity utilization provides a convenient proxy for the output gap without requiring any estimate of potential output.
} 
- all materials goods markets clear, that is equation (8) holds for all $j \in[0,1]$;

- the consumption and capital goods markets clear $Y_{c, t}=\int_{0}^{1} C_{t}(x) d x$ and $Y_{i, t}=I_{t}$; and,

- all factor markets clear, that is $L_{t}(i)=\int_{0}^{1} L_{t}(i, x) d x$ for all $i \in[0,1]$ and $K_{t}=$ $\int_{0}^{1} K_{t}(x) d x$.

Agents take as given the initial values of $K_{0}$ and $R_{-1}$, the sequence of values of the target variables and the sequence of exogenous variables

$$
\left\{A_{c, t}, A_{i, t}, A_{m, t}\right\}_{t=0}^{\infty}
$$

implied by the sequence of shocks

$$
\left\{\epsilon_{c, t}, \epsilon_{i, t}, \epsilon_{m, t}, \epsilon_{r, t}\right\}_{t=0}^{\infty}
$$

The model's first-order conditions are fully described in the Appendix. In simulating the model, we normalize the variables by their balanced growth path values. The normalization is also described in the Appendix. We then log-linearize the normalized equations describing the decentralized equilibrium and solve this system using the Anderson-Moore (1985) algorithm.

\section{Estimation}

We estimate several of the structural parameters of our model using a minimum distance estimator. Specifically, we estimate a VAR on quarterly U.S. data using empirical counterparts to the theoretical variables in our model, and identify two structural shocks using identifying assumptions that are consistent with our theoretical model. We then choose model parameters so as to match the impulse responses to these two shocks implied by the model to those implied by the VAR. ${ }^{4}$ Estimation of model parameters by impulse response function matching has sometimes been criticized for being ad hoc in selecting which properties of the data the model has to match. While we agree that it would also be interesting to explore full information estimation methods, we nevertheless think that the

\footnotetext{
${ }^{4}$ Recent applications of this estimation strategy are Rotemberg and Woodford (1997), Amato and Laubach (2003), Christiano, Eichenbaum, and Evans (2003), and Altig, Christiano, Eichenbaum, and Linde (2002).
} 
estimation undertaken here is valuable precisely because we focus on properties of the data that have a clear structural interpretation. In this section we first describe the VAR and the identification of the two shocks, and then discuss our parameter estimates.

\subsection{VAR Specification and Identification}

The specification of our VAR and the assumptions for identifying structural shocks are in most respects the same as those of Altig, Christiano, Eichenbaum, and Linde (2002), and the reader is referred to that paper. Nine variables are included in the VAR: the first difference of log labor productivity, inflation, log manufacturing capacity utilization, the log labor share, log hours per person, the log nominal consumption-to-output ratio, the log nominal investment-to-output ratio, the nominal funds rate, and (linearly detrended) $\log$ M2 velocity. Labor productivity, the labor share, and hours are the BLS measures for the nonfarm business sector, where the labor share is computed as output per hour times the deflator for nonfarm business output divided by compensation per hour. ${ }^{5}$ Inflation is computed using the GDP deflator. Population is the civilian population age 16 and over. The consumption-to-output ratio is computed as the share of nominal personal consumption of nondurables and services plus nominal government consumption expenditures in nominal GDP. Similarly, the investment-to-output ratio is computed as the share of nominal personal durable goods expenditures plus gross nominal private investment plus nominal government investment expenditures in nominal GDP. ${ }^{6}$

Letting $Y_{t}$ denote the vector of variables in the VAR, and $v_{t} \log$ M2 velocity, we view the data in the VAR as corresponding, up to constants, to the model variables

$$
Y_{t}=\left[\Delta\left(y_{m, t}-l_{t}\right), \pi_{m, t}, u_{t}, y_{m, t}-l_{t}-w_{t}, l_{t}, c_{t}+p_{c, t}-y_{m, t}, i_{t}+p_{i, t}-y_{m, t}, r_{t}, v_{t}\right]^{\prime}
$$

where lower case letters denote logs of the model variables. We estimate the VAR over the sample 1960q1 to 2001q4, including four lags of each variable.

\footnotetext{
${ }^{5}$ By contrast, Altig et al. (2002) and Galí, López-Salido, and Vallés (2003) compute labor productivity by dividing real GDP by total hours in the nonfarm business sector, which is problematic because of the trending share of real nonfarm business output in real GDP.

${ }^{6}$ We compute these ratios as shares of GDP, instead of as shares of nonfarm business output because some consumption of goods and services are not produced by the nonfarm business sector. However, this introduces a minor inconsistency in the VAR impulse responses of output, consumption, and investment presented in Figures 1 and 2. The latter two are constructed by adding the responses of the respective log ratios to the response of nonfarm business output.
} 
Following a number of other recent studies, we are interested in identifying two structural shocks, a permanent shock to the level of technology (in terms of our model, in the intermediate goods sector), and a transitory shock to the funds rate. To identify these shocks, we use one long-run and two short-run identifying restrictions. The short-run identifying restrictions are the usual ones, that the second-to-last and the last variable in the VAR (the funds rate and velocity) are Wold-causal for the preceding variables. Writing the structural form of the VAR as

$$
A_{0} Y_{t}=\text { constant }+A(L) Y_{t-1}+\varepsilon_{t}
$$

the short-run assumptions imply that the last two columns of the contemporaneous multiplier matrix $A_{0}$ have all zeros above the main diagonal. The eighth element of $\varepsilon_{t}$ is identified as the funds rate shock. The long-run identifying restriction is the one proposed by Galí (1999) and further explored in Francis and Ramey (2002) and Altig et al. (2002), that permanent shocks to technology are the only shocks to have a permanent effect on labor productivity. Using this assumption, we identify the first element of $\varepsilon_{t}$ as the technology shock. ${ }^{7}$ This implies that the first row of the matrix of long-run (cumulative) effects of $\varepsilon_{t}$ on $Y_{t},(I-A(1))^{-1} A_{0}^{-1}$, consists of zeros except for the first element.

In order to estimate the VAR in structural form, we need a further set of assumptions to just-identify the elements of $A_{0}$. We follow Altig et al. (2002) in assuming that the submatrix consisting of columns 2-7 and rows 2-7 of $A_{0}$ is lower triangular. This assumption is without loss of generality as we do not attach any structural interpretation to elements 2 through 7 of $\varepsilon_{t}$. With these assumptions, we estimate the first equation of the structural VAR imposing the long-run restrictions in the manner of Shapiro and Watson (1988) by including contemporaneous and lagged variables of elements 2 through 7 of $Y_{t}$ in first-differenced form. To control for simultaneity, we estimate the equation by 2SLS, using a constant and $Y_{t-1}, \ldots, Y_{t-4}$ as first-stage regressors for elements 2 through 7 of $Y_{t}$. We then sequentially estimate equations 2 through 7 by IV, using the residuals from the previous regressions as instruments for contemporaneous variables. Equations 8 and 9 can be estimated by OLS by virtue of our short-run identifying assumptions.

The solid lines in the panels of Figure 1 show the impulse responses to a permanent technology shock, scaled such that the long-run response of output, its components, and the

\footnotetext{
${ }^{7}$ Other shocks, including those to investment goods sector productivity and the tax rate on capital income, can affect the level labor productivity in the long run. See, for example, Fisher (2002).
} 
real wage are equal to 1 . We omit the responses of velocity, as money does not appear in our model, and instead show those of labor productivity. ${ }^{8}$ The dashed-dotted lines present onestandard deviation bands around the impulse responses, computed by bootstrap methods. ${ }^{9}$ Our results resemble those in Altig et al. (2002). As those authors discuss at length, a controversial result from the VAR is that hours rise in response to a positive technology shock. This finding contrasts to those of Galí (1999) and Basu, Fernald, and Kimball (1998), who find that a technology shock induces a decline in hours that lasts for a few quarters. Altig et al. provide evidence that one explanation for the difference between their findings and those of Galí is that in their VAR log per capita hours enter in levels, instead of in first differences. Because our model implies that per capita hours are stationary, we prefer to specify the VAR with per capita hours in levels. The responses shown by the solid lines in Figure 1 are similar to those shown in Altig et al. Figure 2 shows the impulse responses of the variables to a funds rate shock. The estimated responses of output and its components, labor productivity, the real wage, and inflation to a funds rate shock are consistent with many other studies on the effects of monetary policy, and are very similar to those presented in Altig et al.

\subsection{Parameter Estimates}

With the VAR impulse responses to a funds rate shock and a technology shock in hand, we proceed to estimate 14 parameters of our model. The decision as to which parameters to estimate and which ones to calibrate is (loosely) based on how informative the impulse responses are for the parameters. We calibrate those parameters, such as steady-state growth rates, that have little effect on the dynamic responses to shocks. The remaining parameters are estimated by minimizing the squared deviations of the responses of eight variables $\left(y_{m, t}, c_{t}, i_{t}, l_{t}, u_{t}, w_{t}, \pi_{m, t}, r_{t}\right)$ to the two identified shocks implied by the model from those implied by the VAR. For the technology shock we use the responses in quarters 0 through 20 following the shock; for the funds rate shock, we use the responses in quarters 1

\footnotetext{
${ }^{8}$ Our reason for including velocity in the VAR is to facilitate comparison of our VAR with that of Altig et al. (2002), who include velocity.

${ }^{9}$ To prevent the standard error bands from diverging over time, we discard those draws for which the implied reduced-form VAR was estimated to be unstable. Specifically, we discard those draws for which the largest eigenvalue of the coefficient matrix in the reduced form, written in companion form, exceeds .995, which is the case for about 15 percent of all draws.
} 
through 20, since the responses in the quarter of the shock are determined by the identifying assumption. (The impulse responses for the eight variables following the two identified shocks, recive equal weights in our estimation.)

The growth, depreciation, inflation, and interest rates shown in Table 2 and the rate of time preference $\beta$ are expressed at annual rate. The calibrated model parameters are shown in the upper panel. The endowment $\bar{L}$ is normalized to 1 . The value $\alpha=.3$ is consistent with an average labor share in the nonfarm business sector over 1952q1 to 2000q4 of .64 under the assumption of a 10 percent markup in intermediate goods markets (which is a bit lower than our markup estimate, see below). The value of $\delta$ is compatible with our use of a comprehensive measure of capital including residential and nonresidential structures. The gross growth rate $\Gamma_{m}$ in the intermediate goods sector is unobserved, and hence we normalize it to 1 . The growth rates $\Gamma_{c}$ and $\Gamma_{i}$ are based on the average growth rates of our consumption and investment aggregates over the period 1960q1 to 2001q4, which are 3.1 percent and 5.7 percent respectively. The steady-state inflation rate in one sector has to be calibrated; given our assumptions about growth rates in the various sectors, the inflation rate in one sector determines the inflation rates in the others, as well as wage inflation. We choose to calibrate inflation in the consumption sector to 2 percent at an annual rate.

The estimated parameters are shown in the middle panel of the table, with standard errors in parentheses. Standard errors are computed using the Jacobian matrix from the numerical optimization routine and the empirical estimate of the covariance matrix of the impulse responses from the bootstrap. The coefficients of the model are generally estimated with good precision.

One feature of both sets of impulse responses is that real investment, hours, and utilization display prolonged hump-shaped responses to the shocks. Consumption follows a similar pattern in the response to the monetary policy shock, but monotonically rises to its new level in response to the technology shock. In the case of a permanent technology shock, Rotemberg and Woodford (1996) demonstrated that DGE models without intrinsic inertia will not display such hump-shaped patterns; instead, these variables jump on impact and adjust monotonically to their new steady-state values.

Not surprisingly, in estimating the model, we find a significant role for inertia in consumption (in the form of habit persistence) and in investment (in the form of adjustment costs) is needed to match these moments. Our estimate of the habit parameter $\eta$ is close to 
Table 1: Structural Parameter Estimates

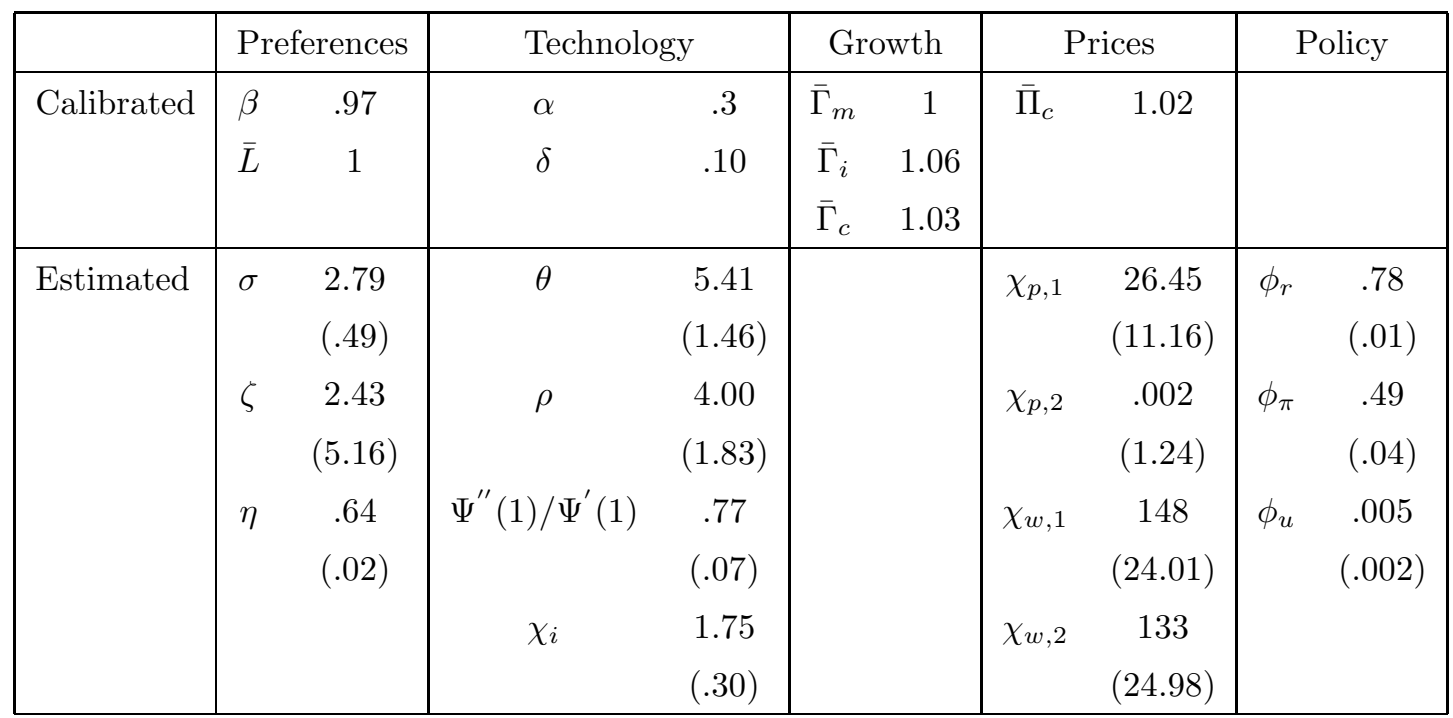

the value estimated by Boldrin, Christiano, and Fisher (2001), Smets and Wouters (2002), and Christiano, Eichenbaum, and Evans (2003), but smaller than the estimate reported in Fuhrer (2000). Our estimate of $\chi_{i}$, the adjustment cost parameter in investment, is smaller than the value of 3.60 reported in Christiano et al., or 6.77 reported in Smets and Wouters. Still, this degree of inertia in investment is sufficient to deliver the distinctive hump-shaped response of investment seen implied by the data.

A second noteworthy feature of the impulse responses is the difference of the impulse responses of inflation to the two shocks. Interestingly, in response to the technology shock inflation drops on impact and then returns to steady state relatively quickly. This pattern is inconsistent with a high degree of intrinsic inflation inertia, as discussed in the following section. The response of inflation to the monetary policy shock is gradual and persistent, suggesting inflation inertia or some other deviation from standard price-setting models.

For the price equation, our estimates imply no intrinsic inflation inertia with the estimated value of $\chi_{p, 2}$ being near zero, reflecting the response to the technology shock. In contrast, we find evidence of intrinsic nominal wage inflation inertia, as evidenced by the estimated value of $\chi_{w, 2}$ exceeding 100 with an estimated standard error of about 25 . We return to a detailed analysis of the estimates of the wage and price equations in the following section.

Rounding out the remainder of the estimates, we find a value of the intertemporal 
elasticity of substitution in consumption (equal to the inverse of $\sigma$ ) well below unity, broadly consistent with results in the literature. ${ }^{10}$ The estimated aggregate labor supply elasticity, based on our estimate of $\zeta$, is above 4, higher than micro-based studies but consistent with other macro-based estimates. The values of $\theta$ and $\rho$ imply steady-state markups in intermediate goods and labor markets of 23 percent and 33 percent, respectively. Our estimate of the elasticity of the utilization cost function $\Psi^{\prime \prime}(1) / \Psi^{\prime}(1)$ implies greater costs from variations in capital utilization than the estimates of Christiano et al. (2001), Altig et al. (2002), or Smets and Wouters (2002) do, although some of the difference between our estimate and others may be due to alternative formulations of utilization costs used in those studies. Our estimates of the parameters of the monetary policy rule, $\phi_{r}, \phi_{\pi}$, and $\phi_{u}$, are broadly consistent with the findings of many other studies that estimate monetary policy reaction functions, such as that of Clarida, Galí, and Gertler (2000).

The dashed lines in Figure 1 present the impulse responses implied by the model under our parametrization to a permanent unanticipated increase in technology that raises $y_{m, t}, c_{t}, i_{t}, l_{t}$, and $w_{t}$ in the long run by one percent. Figure 2 shows the responses to a one percentage point shock to the funds rate, computed under the assumption that no other variable can respond contemporaneously to this shock. The model matches the responses to the technology shock very well across the board. Compared to the VAR impulse responses, the model impulse responses to a funds rate shock of $y_{m, t}, c_{t}, i_{t}, l_{t}$, and $\pi_{m, t}$ are of approximately same magnitude, but appear to be front-loaded, in that the VAR impulse responses reach their trough several quarters after the model responses.

\section{$5 \quad$ Wage and Price Inertia}

In this section, we take a closer look at the estimates of the price and wage equations and compare our results to others in the literature. One advantage of the polynomial adjustment cost model is that it nests the standard quadratic adjustment cost model as a special case. For example, in the case of prices, the restriction $\chi_{p, 2}=0$ yields the quadratic adjustment cost model which is closely related to the Calvo model. A second advantage is that one can

\footnotetext{
${ }^{10}$ We should note that our low estimate of the intertemporal elasticity of substitution, combined with our values for $\beta$ and $\Gamma_{c}$, imply the so-called "risk-free rate puzzle," that is, they result in a very high steadystate real interest rate $\left(\bar{R} / \bar{\Pi}_{c}\right)$ of about 12 percent at annual rate (and a correspondingly low steady-state capital-output ratio).
} 
express the resulting price and wage equations in terms of leads and lags of the dependent variables and the contemporaneous driving variable.

The point estimates for the adjustment cost parameters for price and wage setting, together with the other parameters of our model, yield the following coefficients in the loglinearized price and wage inflation equations (see the Appendix for details on the derivation):

$$
\begin{aligned}
& \pi_{m, t}=.000 \pi_{m, t-1}+.979 E_{t} \pi_{m, t+1}-.000 E_{t} \pi_{m, t+2}+.163 m c_{m, t} \\
& \pi_{w, t}=.244 \pi_{w, t-1}+.984 E_{t} \pi_{w, t+1}-.234 E_{t} \pi_{w, t+2}+.004\left(m r s_{t}-w_{t}\right)
\end{aligned}
$$

where $m c_{m, t}$ is $\log$ relative marginal cost, $m r s_{t}$ is the log of the marginal rate of substitution, and $w_{t}$ is the real wage rate.

Our estimate of the pace of price adjustment is close to those of other studies, as indicated by the relative magnitude of the coefficient on the driving variable, real marginal cost. Translated into terms equivalent to Calvo contracts, our estimates indicate a mean duration of price contracts of only about 2 quarters. The implied estimate of price contract duration is almost the same as that of Chistiano, Eichenbaum, and Evans (2003) who estimate a 2-1/2 quarter mean duration and about half that of Galí and Gertler (1999) who find a mean price contract duration of about one year. ${ }^{11}$ Our estimate is also consistent with Blinder's (1994) survey evidence suggesting a three-quarter duration, as well as other survey evidence reported in Taylor (1999).

We find that wages are far more sluggish than prices with an implied mean contract duration of about $3-1 / 2$ years. ${ }^{12}$ Our estimate of the degree of wage inertia is considerably higher than that of Altig, Christiano, Eichenbaum, and Linde (2002), who estimate about a three quarter mean duration of nominal wages; however, based on the technology shock alone, they find even longer wage contract duration that we do. Our estimate is also well above that implied by direct evidence on wage behavior which suggests average contract durations of one year or shorter (see Taylor 1999). The evidence on contract duration in Europe differs considerably from that in the United States. Smets and Wouters (2002),

\footnotetext{
${ }^{11}$ Our estimation methodology is very similar to that of Christiano et al. (2003). The differences in our estimates reflect differences in the estimated VAR and differences in the weighting of the impulse responses in the distance measure we are minimizaing. Christiano et al. weight the impulse responses by the inverse of their standard errors, while we apply equal weights.

${ }^{12}$ Brayton, Levin, Tryon, and Williams (1997) also find that wages are very sluggish in the Federal Reserve Board's estimated macro model that uses a more general form of the polynomial adjustment cost model than that employed here.
} 
using European data, get the opposite result to ours: they find mean price contract duration of over $2-1 / 2$ years and mean wage contract duration of only one year.

In order to compare our estimates of inertia in the rate of change of prices and wages to those from other studies, it is useful to map our parameter coefficients into implied reducedform coefficients on lagged inflation. Because the polynomial adjustment cost specificationin contrast to the variations of Calvo price setting developed in Galí and Gertler (1999) and Smets and Wouters (2002) - involves two leads of inflation, the degree of inertia is no longer equal to the coefficient on the first lag of inflation in the estimated equation. Instead, the degree of inertia is obtained by solving the price and wage inflation equations for the reduced form, and computing the resulting coefficient on the lagged inflation rate.

Our estimates indicate the lack of any inertia in price inflation, a somewhat stronger finding against inflation inertia than that assumed or estimated in the recent literature. It is worth emphasizing that this result is driven entirely by the behavior of inflation in response to the technology shock. If the model were estimated based primarily on the impulse response to the monetary policy shock, the point estimates suggest modest degree of inflation inertia in line with other estimates in the literature mentioned below, but the implications of incorporating such a degree of inflation inertia for the impulse responses of the two shocks are relatively modest.

Ireland (2001) reaches the same conclusion of no intrinsic inflation inertia in an estimated model with polynomial adjustment costs in setting prices. Galí and Gertler (1999) and Sbordone (2002) find that, conditional on a correctly specified driving process of marginal costs, price inflation exhibits a modest amount of intrinsic inertia. In particular, Galí and Gertler estimate a similar price equation on U.S. data and find a lagged inflation coefficient of between 0.08 and 0.38. Galí, Gertler, and Lopez-Salido (2001) obtain similar results using European data, with estimates of the coefficient on lagged inflation ranging between 0.02 and 0.27. Smets and Wouters (2002) estimate their model on Euro-area data and find about 40 percent price indexation, which translates into a coefficient of about 0.28 on lagged inflation in the price inflation equation. Christiano et al. (2003) assume that all non-adjusted prices and wages are indexed to past inflation, implying a coefficient of 0.5 on lagged inflation. ${ }^{13}$ It is worth noting that other estimated similar models, that use the

\footnotetext{
${ }^{13}$ The price contracting model of Fuhrer and Moore (1995) also possesses, to a first approximation, this property.
} 
output or unemployment gap as the driving variables, tend to imply substantially more intrinsic inflation inertia than we do (for examples see Orphanides and Williams, 2002, and Rudebusch, 2002).

Based on our estimates, the persistent responses of inflation to monetary policy and technology shocks is explained by the persistence in wages owing in part to the high degree of estimated wage inertia. In addition to sluggish adjustment of the level of the wage, we find evidence of wage inflation inertia, in contradiction to standard wage contracting models. Our estimates imply 32 percent wage indexation. This finding is less than that of Smets and Wouters (2002), who estimate, based on Euro-area data, about 66 percent wage indexation. As in the case of prices, Christiano et al. (2001) assume that all non-adjusted prices and wages are indexed to past inflation.

Interestingly, the presence of sticky nominal wages improves the model's fit to the impulse responses of not only wages and prices, but also real variables. The dashed-dotted lines in Figures 3 and 4 show the response using the estimated model but imposing flexible nominal wages. The deterioration in fit relative to the baseline estimated model, shown by the dash-dotted lines for comparison, is striking. By damping and slowing the responses of real wages to shocks, wage inertia acts as a propagation mechanism for the real side of the economy, with the peak responses of hours and utilization greater than would be the case under sticky wages.

Note also that the marginal effect of nominal wage inflation inertia is relatively small. The thin solid line shows the responses with sticky wages but no wage inflation inertia (that is, with $\chi_{w, 2}=0$ imposed). Thus, in terms of the impulse responses what is crucial is the presence of sticky wages, and not necessarily sticky wage inflation. Our finding that nominal wage rigidity is crucial for understanding the dynamic responses to shocks confirms that of Christiano et al. (2003). However, unlike Christiano et al., who assume full indexation of wages and prices, we find that indexation is relatively unimportant for explaining the responses to shocks.

\section{Conclusion}

The nature of nominal inertia is a crucial issue of monetary policy. Much of the past research in this area has focused on the degree of inflation inertia relative to the sticky- 
price benchmark of Calvo (1983). We reexamine the issue of intrinsic inflation inertia in the context of identified shocks to technology and monetary policy from a VAR. We find that inflation shows no signs of inertia in response to a technology shock. We then estimate a micro-founded dynamic general equilibrium model using a flexible specification that nests the standard sticky-wage and sticky-price models but allows for inertia in both wage and price inflation. Consistent with the evidence from the impulse response to the technology shock, we find no evidence of intrinsic inertia in price inflation. Our findings provide some additional support for the standard sticky-price model, as long as it is specified in terms of marginal costs, consistent with the findings of Galí and Gertler (1999) and others.

We have focussed on the responses to shocks to technology because they are arguably least contaminated by misspecification of monetary policy and other macroeconomic relationships captured in the VAR. That said, shocks to technology represent a relatively small portion of aggregate fluctuations, so one must treat these results with caution. Further progress is needed in clearly identifying the responses of price and wage inflation to other shocks to supply and demand.

According to our estimated model, the persistence in inflation seen in the data is driven in the model by persistent movements in marginal costs resulting from highly inertial nominal wages. This extreme sluggishness in aggregate wages conflicts with microeconomic evidence that wages adjust at an annual frequency or more often. This discrepancy between theory and evidence suggests a fruitful avenue for future research is the development and estimation of richer models of wage determination.

\section{References}

[1] Altig, David, Lawrence J. Christiano, Martin Eichenbaum, and Jesper Linde. "Technology Shocks and Aggregate Fluctuations." Manuscript, June 2002.

[2] Amato, Jeffery D., and Thomas Laubach. "Estimation and Control of an OptimizationBased Model with Sticky Prices and Wages." Journal of Economic Dynamics and Control 27 May (2003), 1163-1180.

[3] Anderson, Gary and George Moore. "A Linear Algebraic Procedure for Solving Linear Perfect Foresight Models." Economics Letters 17 (1985), 247-252. 
[4] Basu, Susanto, and Miles S. Kimball. "Long-Run Labor Supply and the Elasticity of Intertemporal Substitution for Consumption." Manuscript, University of Michigan, April 2002.

[5] Basu, Susanto, John Fernald, and Miles S. Kimball. "Are Technology Improvements Contractionary?" Federal Reserve Board, International Finance Discussion Papers 625, September 1998.

[6] Blinder, Alan S. "On Sticky Prices: Academic Theories Meet the Real World." in Monetary Policy In N. Gregory Mankiw (ed), Chicago: University of Chicago Press (1994), 117-150.

[7] Boldrin, Michele, Lawrence J. Christiano, and Jonas Fisher. "Habit Persistence, Asset Returns, and the Business Cycle," American Economic Review 91 (2001), 149-166.

[8] Brayton, Flint, Andrew T. Levin, Ralph Tryon, and John C. Williams. "The Evolution of Macro Models at the Federal Reserve Board." Carnegie Rochester Conference Series on Public Policy 47 (1997), 43-81.

[9] Calvo, Guillermo A. "Staggered Prices in a Utility-Maximizing Framework." Journal of Monetary Economics 12 (1983), 383-398.

[10] Christiano, Lawrence J., Martin Eichenbaum, and Charles L. Evans. "Nominal Rigidities and the Dynamic Effects of a Shock to Monetary Policy." Manuscript, August 2003.

[11] Clarida, Richard, Jordi Galí, and Mark Gertler. "Monetary Policy Rules and Macroeconomic Stability: Evidence and Some Theory." Quarterly Journal of Economics 115 (2000), 147-180.

[12] Edge, Rochelle M., Thomas Laubach, and John C. Williams. "Monetary Policy and the Effects of a Shift in the Growth Rate of Technology." Manuscript, October 2003.

[13] Erceg, Christopher J., Dale W. Henderson, and Andrew T. Levin. "Optimal Monetary Policy with Staggered Wage and Price Contracts." Journal of Monetary Economics 46 (2000), 281-313. 
[14] Erceg, Christopher J., and Andrew T. Levin. "Imperfect Credibility and Inflation Persistence." Journal of Monetary Economics 50 (2003), 915-944.

[15] Estrella, Arturo and Jeffrey C. Fuhrer. "Dynamic Inconsistencies: Counterfactual Implications of a Class of Rational Expectations Models." American Economic Review 92 (2002), 1013-28.

[16] Fisher, Jonas D. M. "Technology Shocks Matter." Federal Reserve Bank of Chicago Working Paper No. 2002-12.

[17] Francis, Neville, and Valerie A. Ramey. "Is the Technology-Driven Real Business Cycle Hypothesis Dead? Shocks and Aggregate Fluctuations Revisited." Manuscript, December 2001.

[18] Fuhrer, Jeffrey C. "The (Un)Importance of Forward-Looking Behavior in Price Specifications." Journal of Money, Credit, and Banking 29 (1997a), 338-50.

[19] Fuhrer, Jeffrey C. "Towards a Compact, Empirically-Verified Rational Expectations Model for Monetary Policy Analysis." Carnegie-Rochester Conference Series on Public Policy 47 (1997b), 197-230.

[20] Fuhrer, Jeffrey C. "Habit Formation in Consumption and Its Implications for Monetary-Policy Models." American Economic Review 90 (2000), 367-390.

[21] Fuhrer, Jeffrey C. and George R. Moore "Inflation Persistence." Quarterly Journal of Economics 110 (1995), 127-159.

[22] Galí, Jordi. "Technology, Employment, and the Business Cycle: Do Technology Shocks Explain Aggregate Fluctuations?" American Economic Review 89 (1999), 249-271.

[23] Galí, Jordi, and Mark Gertler. "Inflation Dynamics: A Structural Econometric Analysis." Journal of Monetary Economics 44 (1999), 195-222.

[24] Galí, Jordi, Mark Gertler, Mark, and J. David López-Salido. "European Inflation Dynamics." European Economic Review 45 (2001), 1237-70.

[25] Galí, Jordi, J. David López-Salido, and Javier Vallés. "Technology Shocks and Monetary Policy: Assessing the Fed's Performance." Journal of Monetary Economics 50 (2003), 723-743. 
[26] Ireland, Peter. "Sticky-Price Models of the Business Cycle: Specification and Stability." Journal of Monetary Economics 47 (2001), 3-18.

[27] Levin, Andrew T., Volker Weiland, and John C. Williams. "The Performance of Forecast-based Policy Rules under Model Uncertainty," American Economic Review 93 (2003), 622-645.

[28] Kozicki, Sharon, and Peter A. Tinsley. "Vector Rational Error Correction." Journal of Economic Dynamics and Control 23 (1999), 1299-1327.

[29] Orphanides, Athanasios, and John C. Williams. "Monetary Policy Rules with Unknown Natural Rates." Brookings Papers on Economic Activity 2 (2002), 63-145.

[30] Rotemberg, Julio J. "Sticky Prices in the United States." Journal of Political Economy 90 (1982), 1187-1211.

[31] Rotemberg, Julio J., and Michael Woodford. "Real Business-Cycle Models and the Forecastable Movements in Output, Hours, and Consumption." American Economic Review 86 (1996), 71-89.

[32] Rotemberg, Julio J., and Michael Woodford. "An Optimization-Based Econometric Framework for the Evaluation of Monetary Policy." In Ben S. Bernanke and Julio J. Rotemberg (eds.), NBER Macroeconomics Annual 1997, 297-346.

[33] Rudebusch, Glenn D. "Assessing Nominal Income Rules for Monetary Policy with Model and Data Uncertainty." Economic Journal 112 (2002), 402-432.

[34] Sbordone, Argia. "Prices and Unit Labor Costs: A New Test of Price Stickiness." Journal of Monetary Economics 49 (2002), 265-292.

[35] Shapiro, Matthew D., and Mark W. Watson. "Sources of Business Cycle Fluctuations." NBER Macroeconomics Annual 1988, 111-148.

[36] Smets, Frank, and Raf Wouters. "An Estimated Stochastic Dynamic General Equilibrium Model of the Euro Area." European Central Bank Working Paper No. 171, August 2002.

[37] Taylor, John B. "Aggregate Dynamics and Staggered Contracts." Journal of Political Economy 88 (1980), 1-23. 
[38] Taylor, John B. "Staggered Price and Wage Setting in Macroeconomics." In John B. Taylor and Michael Woodford (eds) Handbook of Macroeconomics, Volume 1 (1999), 1009-1050.

[39] Taylor, John B., (ed.) Monetary Policy Rules. Chicago: University of Chicago Press (1999).

[40] Tinsley, Peter A. "Fitting Both Data and Theories: Polynomial Adjustment Costs and Error Correction Decision Rules." Finance and Economics Discussion Series No. 1993-21, Federal Reserve Board. 
Figure 1: VAR and Model Impulse Responses to a Technology Shock
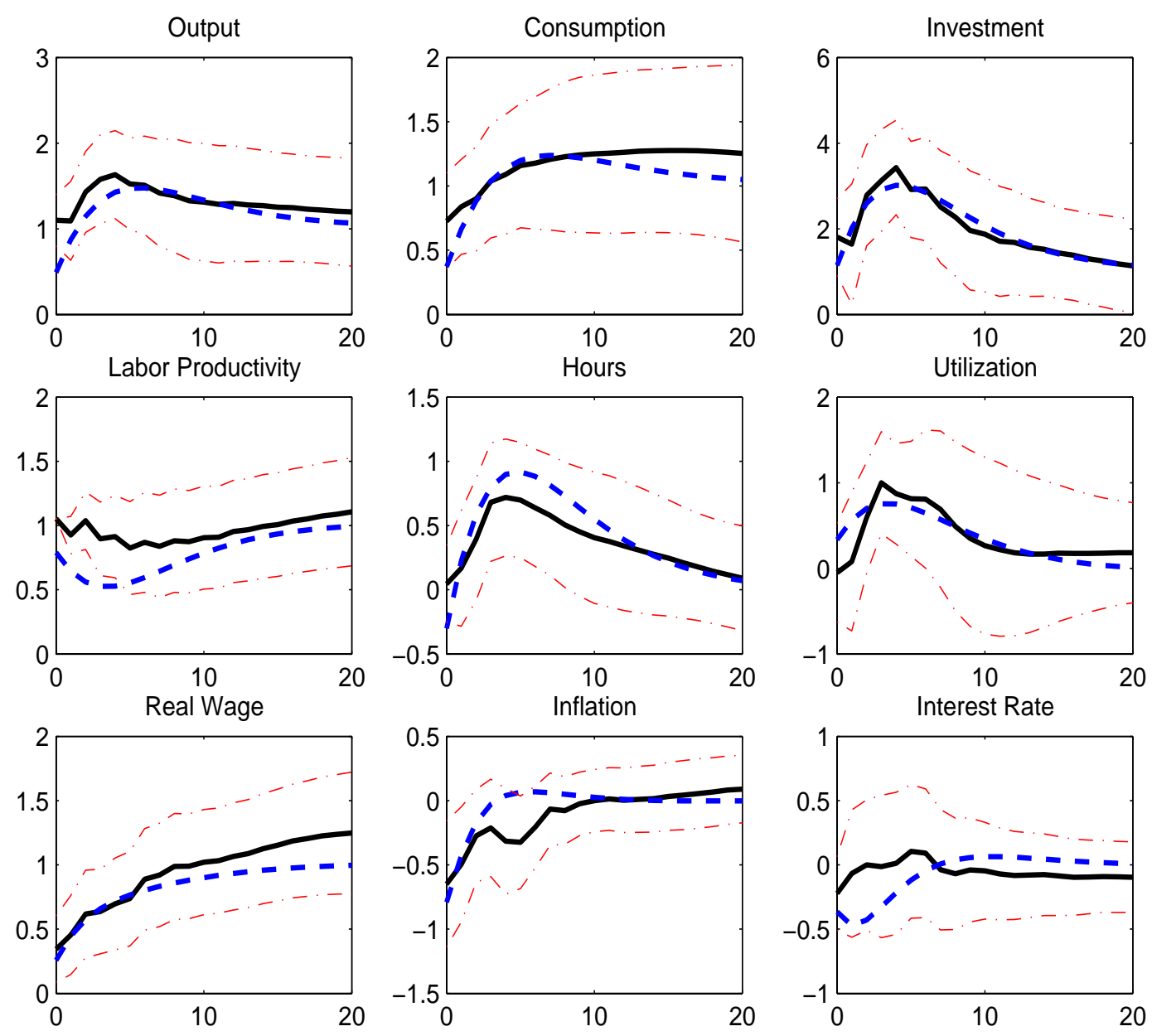

Notes: The solid lines show the impulse responses implied by the VAR to an identified technology shock that in the long-run raises output and its components by one percent. The dashed lines show the impulse responses implied by the model to a permanent onepercent shock to technology in sector $m$. The dashed-dotted lines are one standard error confidence intervals around the VAR responses. 
Figure 2: VAR and Model Impulse Responses to a Funds Rate Shock
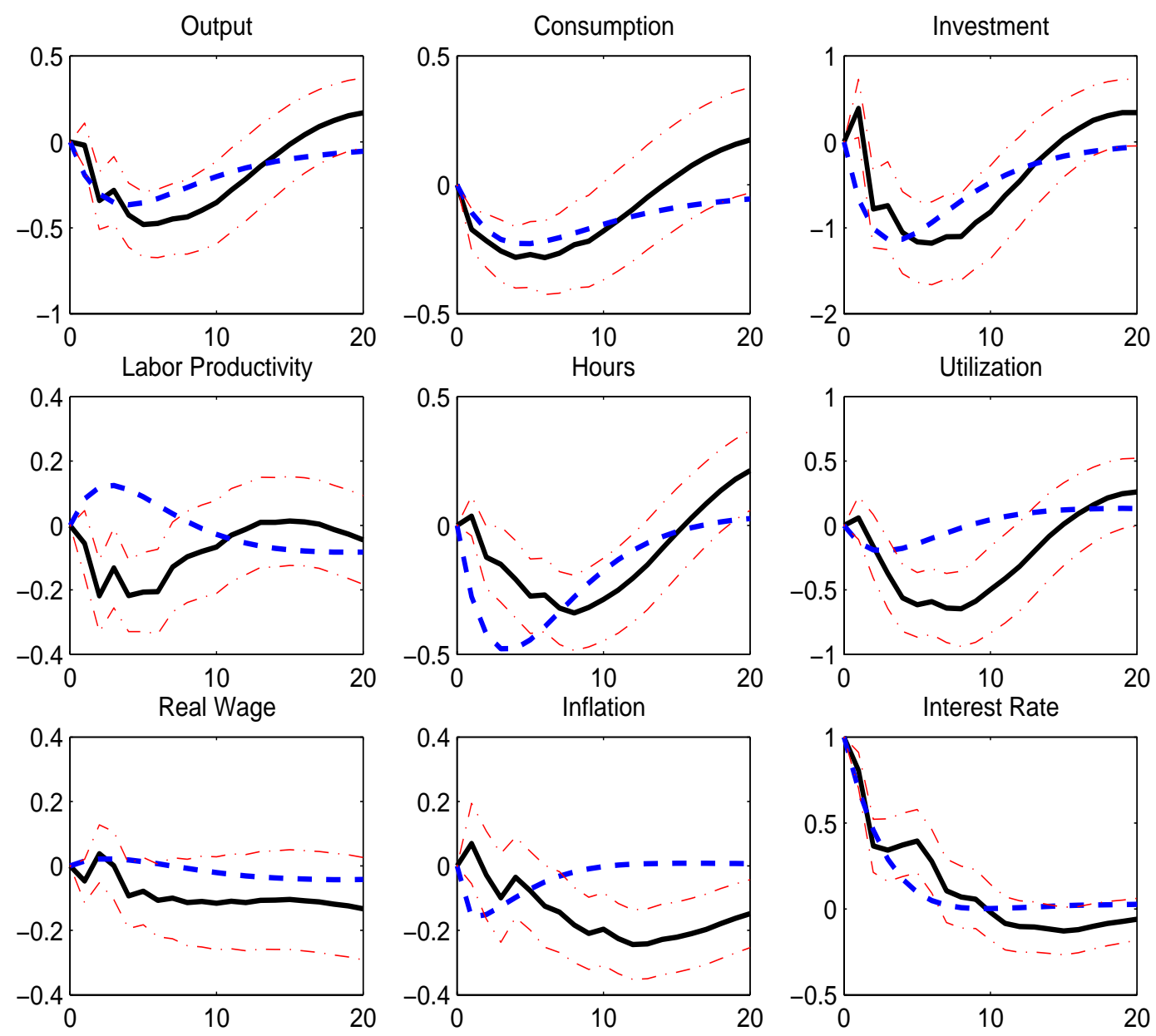

Notes: The solid lines show the impulse responses implied by the VAR following a one percent funds rate shock. The dashed lines show the impulse responses implied by the model to the same shock under the assumption that the contemporaneous response of all variables other than the funds rate is zero. The dashed-dotted lines are one standard error confidence intervals around the VAR responses. 
Figure 3: VAR and Model Impulse Responses to a Technology Shock
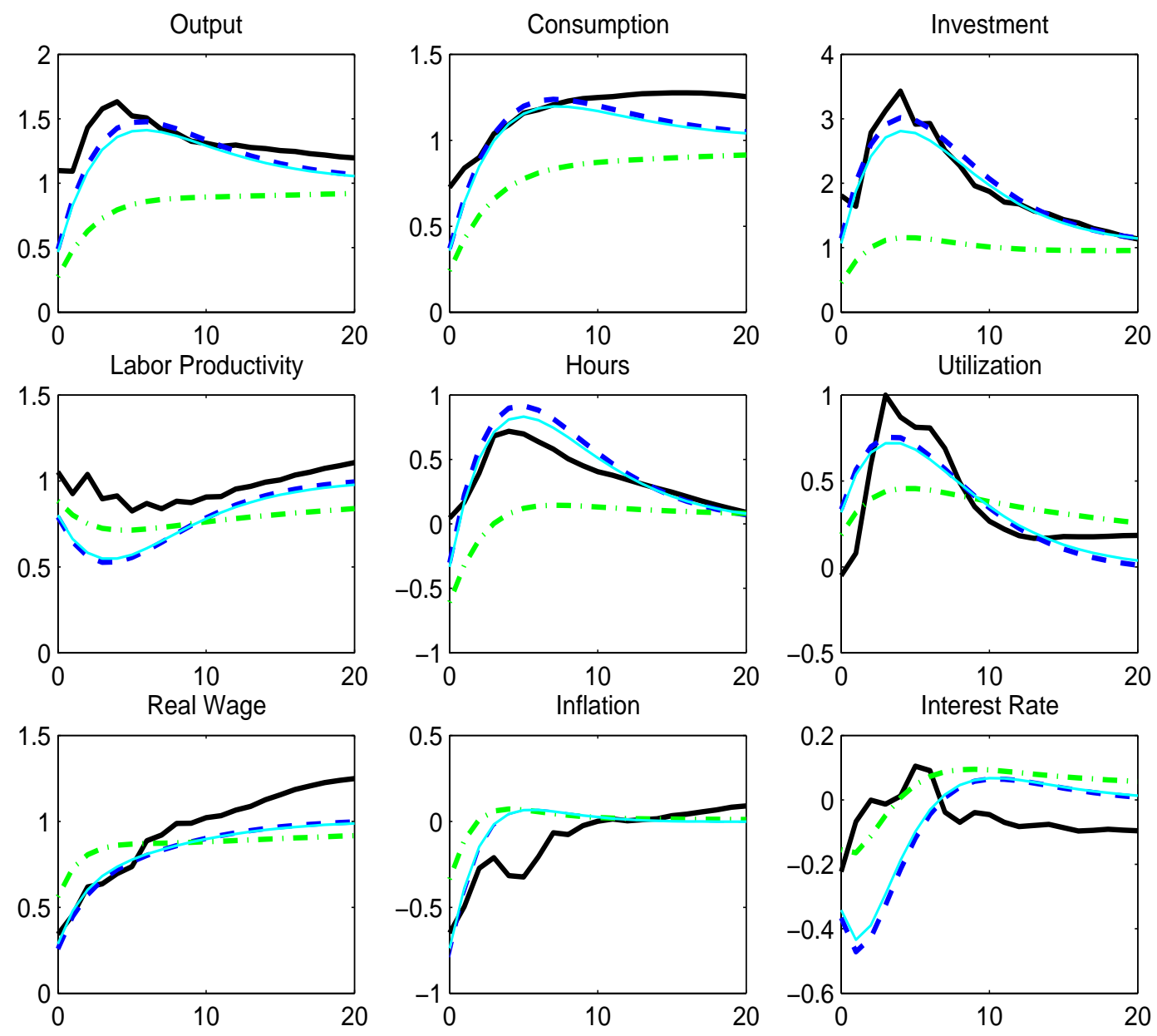

Notes: The thick solid lines show the impulse responses implied by the VAR to an identified technology shock that in the long-run raises output and its components one percent. The dashed lines show the impulse responses implied by the model to a permanent one-percent shock to technology in sector $m$. The dashed-dotted lines show the model responses with flexible wages $\left(\chi_{w, 1}=\chi_{w, 2}=0\right)$. The thin solid lines show the model responses with sticky wages but no intrinsic wage inflation inertia $\left(\chi_{w, 2}=0\right)$. 
Figure 4: VAR and Model Impulse Responses to a Funds Rate Shock
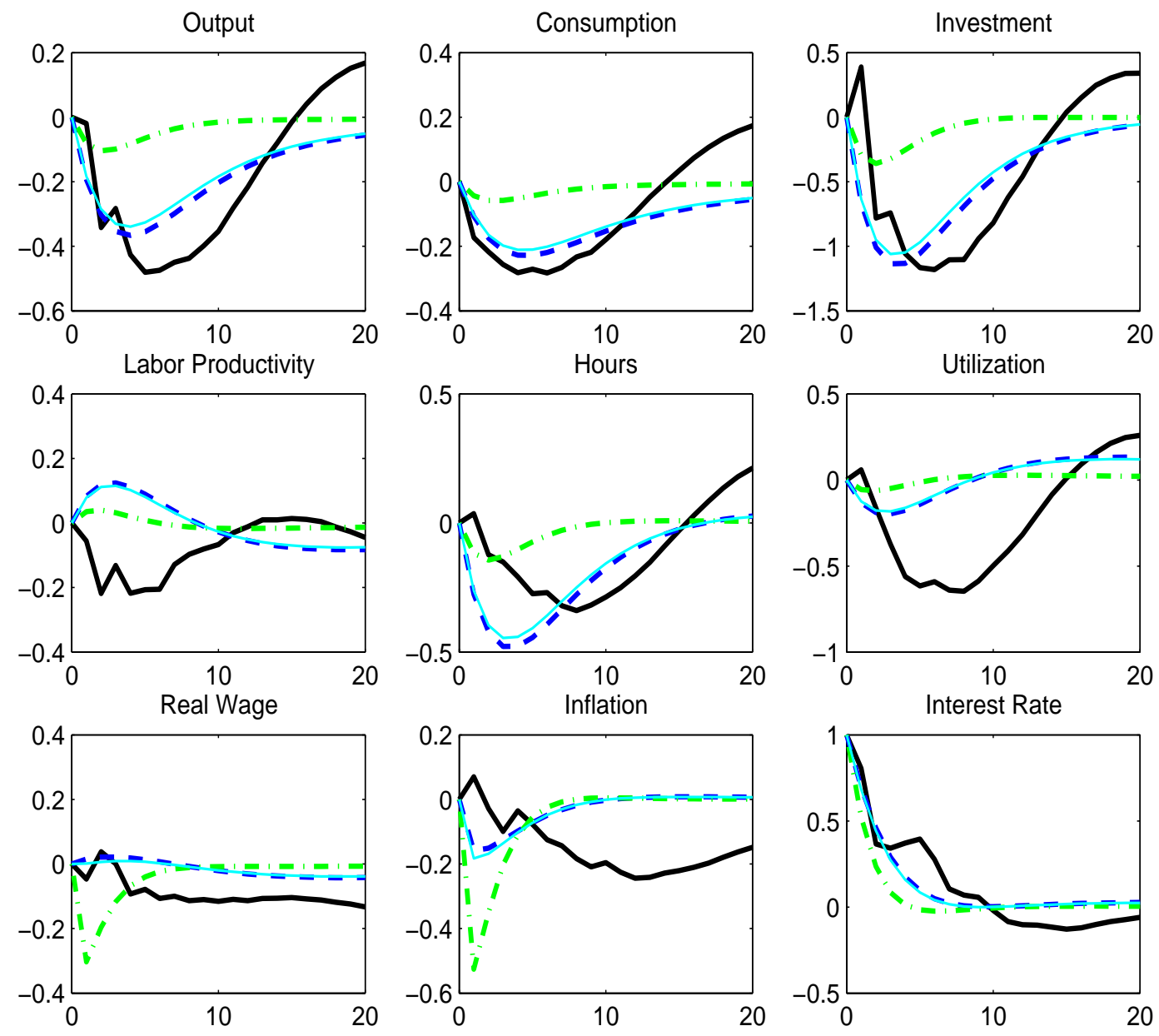

Notes: The thick solid lines show the impulse responses implied by the VAR following a one percent funds rate shock. The dashed lines show the impulse responses implied by the model to the same shock under the assumption that the contemporaneous response of all variables other than the funds rate is zero. The dashed-dotted lines show the model responses with flexible wages $\left(\chi_{w, 1}=\chi_{w, 2}=0\right)$. The thin solid lines show the model responses with sticky wages but no intrinsic wage inflation inertia $\left(\chi_{w, 2}=0\right)$. 


\section{Appendix}

In this appendix, we derive and log-linearize the first-order conditions and describe the normalization of variables along the balanced growth path.

\section{First-order Conditions}

The consumption and capital goods producing firms' cost minimization problems (equation 7 for $s=c$ and $i$ ) yield demand functions from each final-good producing sector for each of the intermediate goods:

$$
Y_{m, c, t}(j)=\left(\frac{P_{m, t}(j)}{P_{m, t}}\right)^{-\theta} \frac{Y_{c, t}}{A_{c, t}^{1-\alpha}} \text { and } Y_{m, i, t}(j)=\left(\frac{P_{m, t}(j)}{P_{m, t}}\right)^{-\theta} \frac{Y_{i, t}}{A_{i, t}^{1-\alpha}}
$$

where the variable $P_{m, t}$, which has the interpretation of being the competitive price for the cost-minimizing bundle of materials goods, is defined:

$$
P_{m, t}=\left(\int_{0}^{1}\left(P_{m, t}(j)\right)^{1-\theta} d j\right)^{\frac{1}{1-\theta}} .
$$

The demand functions in equation (18) imply an economy-wide demand for each intermediate good of:

$$
Y_{m, t}(j)=Y_{m, c, t}(j)+Y_{m, i, t}(j)=\left(\frac{P_{m, t}(j)}{P_{m, t}}\right)^{-\theta}\left(\frac{Y_{c, t}}{A_{c, t}^{1-\alpha}}+\frac{Y_{i, t}}{A_{i, t}^{1-\alpha}}\right) .
$$

In the symmetric equilibria that we consider (that is, where $P_{m, t}(j)=P_{m, t}$ for all $j$ ) this demand function simplifies to:

$$
Y_{m, t}(j)=\left(\frac{Y_{c, t}}{A_{c, t}^{1-\alpha}}+\frac{Y_{i, t}}{A_{i, t}^{1-\alpha}}\right)
$$

The competitive prices of consumption and capital goods are:

$$
P_{c, t}=P_{m, t} A_{c, t}^{-(1-\alpha)} \text { and } P_{i, t}=P_{m, t} A_{i, t}^{-(1-\alpha)} .
$$

The capitalists profit-maximization problem (equation 13) yields the following first-order conditions:

$$
\begin{aligned}
P_{i, t} I_{t} & =\exp \left[-\frac{\chi_{i}}{2}\left(\frac{I_{t}}{I_{t-1}}-\Gamma_{i}\right)^{2}\right]\left(1-\chi_{i} \frac{I_{t}}{I_{t-1}}\left(\frac{I_{t}}{I_{t-1}}-\Gamma_{i}\right)\right) Q_{k, t} I_{t} \\
& +\beta E_{t}\left[\frac{\Lambda_{c, t+1} / P_{c, t+1}}{\Lambda_{c, t} / P_{c, t}} \exp \left[-\frac{\chi_{i}}{2}\left(\frac{I_{t+1}}{I_{t}}-\Gamma_{i}\right)^{2}\right] \chi_{i} \frac{I_{t+1}}{I_{t}}\left(\frac{I_{t+1}}{I_{t}}-\Gamma_{i}\right) Q_{k, t+1} I_{t+1}\right] \\
Q_{k, t} & =\beta E_{t}\left[\frac{\Lambda_{c, t+1} / P_{c, t+1}}{\Lambda_{c, t} / P_{c, t}}\left(\left((1-\delta) Q_{k, t+1}+R_{k, t+1}\right)\right)\right]
\end{aligned}
$$


The household's utility-maximization problem (equation 15) yields an Euler equation and labor supply schedules. In a symmetric equilibrium, all households make the same consumption and wage decisions. Hence the index $i$ is dropped in the following. Letting $\Lambda_{c, t}$ denote the marginal utility of consumption we define

$$
\Lambda_{c, t}=\left(C_{t}-\eta C_{t-1}\right)^{-\sigma}\left(\bar{L}-L_{t}\right)^{\zeta(1-\sigma)}-E_{t} \beta \eta\left[\left(C_{t+1}-\eta C_{t}\right)^{-\sigma}\left(\bar{L}-L_{t+1}\right)^{\zeta(1-\sigma)}\right] .
$$

Letting $\Lambda_{l, t}$ denote the marginal disutility of labor supply we define

$$
\Lambda_{l, t}=\zeta\left(C_{t}-\eta C_{t-1}\right)^{(1-\sigma)}\left(\bar{L}-L_{t}\right)^{\zeta(1-\sigma)-1} .
$$

This allows us to write the Euler equation as

$$
\frac{\Lambda_{c, t}}{P_{c, t}}=\beta R_{t} E_{t}\left[\frac{\Lambda_{c, t+1}}{P_{c, t+1}}\right]
$$

and the labor supply curve as:

$$
\begin{aligned}
\frac{\Lambda_{l, t}}{\Lambda_{c, t}} L_{t} \rho & =(\rho-1) \frac{W_{t}}{P_{c, t}} L_{t}+\left(\chi_{w, 1}\left(\Pi_{w, t}-\Pi_{w}\right) \Pi_{w, t}+\chi_{w, 2}\left(\frac{\Pi_{w, t}}{\Pi_{w, t-1}}-1\right) \frac{\Pi_{w, t}}{\Pi_{w, t-1}}\right) C_{t} \\
& -\beta E_{t}\left[\frac{\Lambda_{c, t+1}}{\Lambda_{c, t}}\left(\chi_{w, 1}\left(\Pi_{w, t+1}-\Pi_{w}\right) \Pi_{w, t+1}+2 \chi_{w, 2}\left(\frac{\Pi_{w, t+1}}{\Pi_{w, t}}-1\right) \frac{\Pi_{w, t+1}}{\Pi_{w, t}}\right) C_{t+1}\right] \\
& +\beta^{2} E_{t}\left[\frac{\Lambda_{c, t+2}}{\Lambda_{c, t+1}} \frac{\Lambda_{c, t+1}}{\Lambda_{c, t}}\left(\chi_{w, 2}\left(\frac{\Pi_{w, t+2}}{\Pi_{w, t+1}}-1\right) \frac{\Pi_{w, t+2}}{\Pi_{w, t+1}}\right) C_{t+2}\right]
\end{aligned}
$$

The first step of the intermediate-good producing firm's cost-minimization problem equation (9) implies an economy-wide demand schedule for type $i$ labor of:

$$
L_{t}(i)=\int_{0}^{1} L_{t}(i, j) d j=\left(\frac{W_{t}(j)}{W_{t}}\right)^{-\rho} \int_{0}^{1} L_{t}(j) d j=\left(\frac{W_{t}(j)}{W_{t}}\right)^{-\rho} L_{t} .
$$

In the symmetric equilibrium this equation implies that $L_{t}(i)=L_{t}$ for all $i$. The second step of the intermediate-good producing firm's cost-minimization problem equation (11) implies the following first-order conditions:

$$
\begin{aligned}
\alpha \frac{\left(K_{t} U_{t}\right)^{\alpha}\left(A_{m, t} L_{t}\right)^{1-\alpha}}{K_{t}} & =\frac{R_{k, t}}{M C_{m, t}}+\Psi\left(U_{t}\right)\left(A_{i, t}\right)^{-(1-\alpha)} \\
(1-\alpha) \frac{\left(K_{t} U_{t}\right)^{\alpha}\left(A_{m, t} L_{t}\right)^{1-\alpha}}{L_{t}} & =\frac{W_{t}}{M C_{m, t}} \\
\alpha \frac{\left(K_{t} U_{t}\right)^{\alpha}\left(A_{m, t} L_{t}\right)^{1-\alpha}}{K_{t} U_{t}} & =\Psi^{\prime}\left(U_{t}\right)\left(A_{i, t}\right)^{-(1-\alpha)} \\
\left(K_{t} U_{t}\right)^{\alpha}\left(A_{m, t} L_{t}\right)^{1-\alpha} & =Y_{m, t}+K_{t} \Psi\left(U_{t}\right)\left(A_{i, t}\right)^{-(1-\alpha)} .
\end{aligned}
$$


Together these equation imply capital and labor factor demand schedules, an expression for optimal utilization and a marginal cost schedule. The intermediate-good producing firm's profit-maximization problem equation (12) implies a price Phillips curve of:

$$
\begin{aligned}
M C_{m, t} Y_{m, t} \theta & =(\theta-1) P_{m, t} Y_{m, t}+\left(\chi_{p, 1}\left(\Pi_{m, t}-\Pi_{m}\right) \Pi_{m, t}+\chi_{p, 2}\left(\frac{\Pi_{m, t}}{\Pi_{m, t-1}}-1\right) \frac{\Pi_{m, t}}{\Pi_{m, t-1}}\right) P_{m, t} Y_{m, t} \\
& -\beta E_{t}\left[\frac{\Lambda_{c, t+1} / P_{c, t+1}}{\Lambda_{c, t} / P_{c, t}}\left(\chi_{p, 1}\left(\Pi_{m, t+1}-\Pi_{m}\right) \Pi_{m, t+1}+2 \chi_{p, 2}\left(\frac{\Pi_{m, t+1}}{\Pi_{m, t}}-1\right) \frac{\Pi_{m, t+1}}{\Pi_{m, t}}\right) P_{m, t+1} Y_{m, t+1}\right] \\
& +\beta^{2} E_{t}\left[\frac{\Lambda_{c, t+2} / P_{c, t+2}}{\Lambda_{c, t+1} / P_{c, t+1}} \frac{\Lambda_{c, t+1} / P_{c, t+1}}{\Lambda_{c, t} / P_{c, t}}\left(\chi_{p, 2}\left(\frac{\Pi_{m, t+2}}{\Pi_{m, t+1}}-1\right) \frac{\Pi_{m, t+2}}{\Pi_{m, t+1}}\right) P_{m, t+2} Y_{m, t+2}\right] .
\end{aligned}
$$

\section{Balanced Growth}

The first step required in specifying the first-order conditions in terms of stationary variables only is to determine the rates of growth of the non-stationary variables. From equation (2) we know that in the steady state:

$$
\ln \Gamma_{m}=(1-\alpha) \ln \Gamma_{a, m}+\alpha \ln \Gamma_{i}
$$

where $\bar{\Gamma}_{m}$ is the steady-state growth rate of materials goods production, while $\bar{\Gamma}_{a, m}$ is the steady-state growth rate of technology in the materials production function. $\bar{\Gamma}_{i}$ is the steady-state growth rate of investment goods production, which is defined from equation (1) for $s=i$ as:

$$
\ln \Gamma_{i}=(1-\alpha) \ln \Gamma_{a, i}+\ln \Gamma_{a, m}
$$

while $\bar{\Gamma}_{c}$ is the steady-state growth rate of consumption goods production, which is defined from equation (1) for $s=c$ as:

$$
\ln \Gamma_{c}=(1-\alpha) \ln \Gamma_{a, c}+\ln \Gamma_{m}
$$

Equations (35) and (36), can be solved simultaneously to yield

$$
\begin{aligned}
& \ln \Gamma_{m}=\ln \Gamma_{a, m}+\alpha \ln \Gamma_{a, i} \text { and } \\
& \ln \Gamma_{a, i}=\ln \Gamma_{a, m}+\ln \Gamma_{a, i},
\end{aligned}
$$

which then allows us to re-write equation (37):

$$
\ln \Gamma_{c}=\ln \Gamma_{a, m}+\alpha \ln \Gamma_{a, i}+(1-\alpha) \ln \Gamma_{a, c} .
$$


Equations (38) to (40) imply that the following renormalized product market quantity variables are stationary:

$$
\tilde{Y}_{m, t}=\frac{Y_{m, t}}{A_{m, t} A_{i, t}^{\alpha}}, \tilde{Y}_{i, t}=\frac{Y_{i, t}}{A_{m, t} A_{i, t}}, \widetilde{Y}_{c, t}=\frac{Y_{c, t}}{A_{m, t} A_{i, t}^{\alpha} A_{c, t}^{1-\alpha}}, \widetilde{I}_{t}=\frac{I_{t}}{A_{m, t} A_{i, t}} \text {, and } \widetilde{C}_{t}=\frac{C_{t}}{A_{m, t} A_{i, t}^{\alpha} A_{c, t}^{1-\alpha}}
$$

In factor markets, labor input $L_{t}$ is stationary without any renormalization. Capital is rendered stationary by the following renormalization:

$$
\widetilde{K}_{t}=\frac{K_{t}}{A_{m, t} A_{i, t}} .
$$

This normalization implies that while the unnormalized $t+1$ capital stock $K_{t+1}$ is known in period $t$, the normalized $t+1$ capital stock $\widetilde{K}_{t+1}$ is not known until $A_{m, t+1}$ and $A_{i, t+1}$ are realized in period $t+1$. From the equations in (19) and (22) we know that in steady state

$$
\ln \Pi_{m}(j)=\ln \Pi_{m}, \ln \Pi_{c}=\ln \Pi_{m}-(1-\alpha) \ln \Gamma_{a, c}, \text { and } \ln \Pi_{k}=\ln \Pi_{m}-(1-\alpha) \ln \Gamma_{a, i}
$$

where $\Pi_{m}$ is the steady-state aggregate inflation rate in the materials good sector, $\Pi_{m}(j)$ is the steady-state inflation rate for the $j$ th materials goods, and $\Pi_{c}$ and $\Pi_{i}$ are the steadystate inflation rates for consumption and capital goods prices. These conditions imply that the following product price ratios are stationary:

$$
\widetilde{P}_{m, t}(j)=\frac{P_{m, t}(j)}{P_{m, t}}, \widetilde{P}_{c, t}=\frac{P_{c, t}}{P_{m, t}} A_{c, t}^{1-\alpha}, \widetilde{P}_{i, t}=\frac{P_{i, t}}{P_{m, t}} A_{i, t}^{1-\alpha}, \text { and } \widetilde{Q}_{t}=\frac{Q_{k, t}}{P_{m, t}} A_{i, t}^{1-\alpha} .
$$

The capitalists supply schedule, equation (24), implies that the steady-state nominal growth rate of the rental rate on capital is equal to the steady-state capital price inflation rate (that is, $\left.\ln \Pi_{R_{k}}=\ln \Pi_{i}\right)$. The steady-state growth rate of nominal wages, can be inferred from equation (28), which states that it is equal to

$$
\ln \Pi_{w}(i)=\ln \Pi_{w}=\ln \Pi_{m}+\ln \Gamma_{a, m}+\alpha \ln \Gamma_{a, i} .
$$

Consequently, the following real factor prices are also stationary:

$$
\widetilde{W}_{t}(i)=\frac{W_{t}(i)}{P_{m, t} A_{m, t} A_{i, t}^{\alpha}}, \widetilde{W}_{t}=\frac{W_{t}}{P_{m, t} A_{m, t} A_{i, t}^{\alpha}} \text {, and } \widetilde{R}_{k, t}=\frac{R_{k, t}}{P_{m, t}} A_{i, t}^{1-\alpha},
$$

while stationary marginal cost is

$$
\widetilde{M C}_{m, t}(j)=\frac{M C_{m, t}}{P_{m, t}}
$$


Finally it is worth noting from equation (25) that we can perform the following renormalization to make the marginal utility of consumption $\Lambda_{c, t}$ stationary

$$
\widetilde{\Lambda}_{c, t}=\frac{\Lambda_{c, t}}{A_{m, t}^{-\sigma} A_{i, t}^{-\sigma \alpha} A_{c, t}^{-\sigma(1-\alpha)}} .
$$

and while from equation (26) we can make the marginal utility of labor $\Lambda_{h, t}$ stationary with:

$$
\widetilde{\Lambda}_{l, t}=\frac{\Lambda_{h, t}}{A_{m, t}^{(1-\sigma)} A_{i, t}^{(1-\sigma) \alpha} A_{c, t}^{(1-\sigma)(1-\alpha)}} .
$$

\section{First-Order Conditions (with Stationary Variables Only)}

The consumption and capital goods producing firms' cost minimization problems imply a (stationary) economy-wide demand for each intermediate good of:

$$
\widetilde{Y}_{m, t}(j)=\widetilde{Y}_{c, t}(j)+\widetilde{Y}_{i, t}(j)=\left(\widetilde{P}_{m, t}(j)\right)^{-\theta}\left(\widetilde{Y}_{c, t}+\widetilde{Y}_{i, t}\right)
$$

which in the symmetric equilibrium is:

$$
\widetilde{Y}_{m, t}=\tilde{Y}_{m, t}(j)=\tilde{Y}_{c, t}(j)+\tilde{Y}_{i, t}(j)=\tilde{Y}_{c, t}+\tilde{Y}_{i, t} .
$$

The stationary relative prices of the consumption and capital goods are:

$$
\widetilde{P}_{c, t}=1 \text { and } \widetilde{P}_{i, t}=1
$$

The capitalists profit-maximization problem (equation 13) yields the following (stationary) first-order conditions:

$$
\begin{aligned}
\widetilde{I}_{t}=\exp \left[-\frac{\chi_{i}}{2}\left(\frac{\widetilde{I}_{t}}{\widetilde{I}_{t-1}} \Gamma_{i, t}-\Gamma_{i}\right)^{2}\right]\left(1-\chi_{i} \frac{\widetilde{I}_{t}}{\widetilde{I}_{t-1}} \Gamma_{i, t}\left(\frac{\widetilde{I}_{t}}{\widetilde{I}_{t-1}} \Gamma_{i, t}-\Gamma_{i}\right)\right) \frac{\widetilde{Q}_{k, t}}{\widetilde{P}_{i, t}} \widetilde{I}_{t} \\
+\beta E_{t}\left[\frac{\widetilde{\Lambda}_{c, t+1}}{\widetilde{\Lambda}_{c, t}} \frac{\Pi_{i, t+1}}{\Pi_{c, t+1}}\left(\Gamma_{c, t+1}\right)^{-\sigma} \exp \left[-\frac{\chi_{i}}{2}\left(\frac{\widetilde{I}_{t+1}}{\widetilde{I}_{t}} \Gamma_{i, t}-\Gamma_{i}\right)^{2}\right]\right. \\
\left.\times \chi_{i} \frac{\widetilde{I}_{t+1}}{\widetilde{I}_{t}} \Gamma_{i, t+1}\left(\frac{\widetilde{I}_{t+1}}{\widetilde{I}_{t}} \Gamma_{i, t+1}-\Gamma_{i}\right) \frac{\widetilde{Q}_{k, t+1}}{\widetilde{P}_{i, t+1}} \Gamma_{i, t+1} \widetilde{I}_{t+1}\right] \\
\frac{\widetilde{Q}_{k, t}}{\widetilde{P}_{i, t}}=\beta E_{t}\left[\frac{\widetilde{\Lambda}_{c, t+1}}{\widetilde{\Lambda}_{c, t}} \frac{\Pi_{i, t+1}}{\Pi_{c, t+1}}\left(\Gamma_{c, t+1}\right)^{-\sigma}\left((1-\delta) \frac{\widetilde{Q}_{k, t+1}}{\widetilde{P}_{i, t+1}}+\frac{\widetilde{R}_{k, t+1}}{\widetilde{P}_{i, t+1}}\right)\right]
\end{aligned}
$$

The stationary version of the capital evolution equation is:

$$
\Gamma_{i, t+1} \widetilde{K}_{t+1}=(1-\delta) \widetilde{K}_{t}+\widetilde{I}_{t}
$$


The Euler equation and labor supply schedule (equations 27 and 28) from the households utility-maximization problem is:

$$
\widetilde{\Lambda}_{c, t}=\beta E_{t}\left[\left(\frac{R_{t}}{\Pi_{c, t+1}}\left(\Gamma_{c, t+1}\right)^{-\sigma} \widetilde{\Lambda}_{c, t+1}\right)\right]
$$

and the labor supply curve as:

$$
\begin{aligned}
& \frac{\widetilde{\Lambda}_{l, t}}{\widetilde{\Lambda}_{c, t}} L_{t} \rho=(\rho-1) \frac{\widetilde{W}_{t}}{\widetilde{P}_{c, t}} L_{t}+\left(\chi_{w, 1}\left(\Pi_{w, t}-\Pi_{w}\right) \Pi_{w, t}+\chi_{w, 2}\left(\frac{\Pi_{w, t}}{\Pi_{w, t-1}}-1\right) \frac{\Pi_{w, t}}{\Pi_{w, t-1}}\right) \widetilde{C}_{t} \\
& -\beta E_{t}\left[\frac{\widetilde{\Lambda}_{c, t+1}}{\widetilde{\Lambda}_{c, t}}\left(\Gamma_{c, t+1}\right)^{-\sigma}\left(\chi_{w, 1}\left(\Pi_{w, t+1}-\Pi_{w}\right) \Pi_{w, t+1}+2 \chi_{w, 2}\left(\frac{\Pi_{w, t+1}}{\Pi_{w, t}}-1\right) \frac{\Pi_{w, t+1}}{\Pi_{w, t}}\right) \Gamma_{c, t+1} \widetilde{C}_{t+1}\right] \\
& +\beta^{2} E_{t}\left[\frac{\widetilde{\Lambda}_{c, t+2}}{\widetilde{\Lambda}_{c, t+1}} \frac{\widetilde{\Lambda}_{c, t+1}}{\widetilde{\Lambda}_{c, t}}\left(\Gamma_{c, t+2} \Gamma_{c, t+1}\right)^{-\sigma}\left(\chi_{w, 2}\left(\frac{\Pi_{w, t+2}}{\Pi_{w, t+1}}-1\right) \frac{\Pi_{w, t+2}}{\Pi_{w, t+1}}\right) \Gamma_{c, t+2} \Gamma_{c, t+1} \widetilde{C}_{t+2}\right]
\end{aligned}
$$

where the stationary marginal utility of consumption $\widetilde{\Lambda}_{c, t}$ is:

$$
\widetilde{\Lambda}_{c, t}=\left(\widetilde{C}_{t}-\eta \frac{\widetilde{C}_{t-1}}{\Gamma_{c, t}}\right)^{-\sigma}\left(\bar{L}-L_{t}\right)^{\zeta(1-\sigma)}-E_{t} \beta \eta\left[\Gamma_{c, t+1}^{-\sigma}\left(\widetilde{C}_{t+1}-\eta \frac{\widetilde{C}_{t}}{\Gamma_{c, t+1}}\right)^{-\sigma}\left(\bar{L}-L_{t+1}\right)^{\zeta(1-\sigma)}\right]
$$

while the stationary marginal disutility of labor supply $\widetilde{\Lambda}_{l, t}$ is:

$$
\widetilde{\Lambda}_{l, t}=\zeta\left(\widetilde{C}_{t}-\eta \frac{\widetilde{C}_{t-1}}{\Gamma_{c, t}}\right)^{(1-\sigma)}\left(\bar{L}-L_{t}\right)^{\zeta(1-\sigma)-1}
$$

The stationary first-order conditions from the second step of intermediate-good producing firm's cost-minimization problem (equations 30 to 33) are

$$
\begin{aligned}
\alpha \frac{\left(\widetilde{K}_{t} U_{t}\right)^{\alpha}\left(L_{t}\right)^{1-\alpha}}{\widetilde{K}_{t}} & =\frac{\widetilde{R}_{k, t}}{\widetilde{M C}_{m, t}}+\Psi\left(U_{t}\right) \\
(1-\alpha) \frac{\left(\widetilde{K}_{t} U_{t}\right)^{\alpha}\left(L_{t}\right)^{1-\alpha}}{L_{t}} & =\frac{\widetilde{W}_{t}}{\widetilde{M C}_{m, t}} \\
\alpha \frac{\left(\widetilde{K}_{t} U_{t}\right)^{\alpha}\left(L_{t}\right)^{1-\alpha}}{\widetilde{K}_{t} U_{t}} & =\Psi^{\prime}\left(U_{t}\right) \\
\left(\widetilde{K}_{t} U_{t}\right)^{\alpha}\left(L_{t}\right)^{1-\alpha} & =\widetilde{M}_{t}+\widetilde{K}_{t} \Psi\left(U_{t}\right) .
\end{aligned}
$$

The stationary Phillips curve from the intermediate-good producing firm's profit-maximization problem :

$$
\widetilde{M C}_{m, t} \tilde{Y}_{m, t} \theta=(\theta-1) \widetilde{Y}_{m, t}+\left(\chi_{p, 1}\left(\Pi_{m, t}-\Pi_{m}\right) \Pi_{m, t}+\chi_{p, 2}\left(\frac{\Pi_{m, t}}{\Pi_{m, t-1}}-1\right) \frac{\Pi_{m, t}}{\Pi_{m, t-1}}\right) \widetilde{Y}_{m, t}
$$




$$
\begin{aligned}
& -\beta E_{t}\left[\frac{\widetilde{\Lambda}_{c, t+1}}{\widetilde{\Lambda}_{c, t}} \frac{\Pi_{m, t+1}}{\Pi_{c, t+1}}\left(\Gamma_{c, t+1}\right)^{-\sigma}\left(\chi_{p, 1}\left(\Pi_{m, t+1}-\Pi_{m}\right) \Pi_{m, t+1}+2 \chi_{p, 2}\left(\frac{\Pi_{m, t+1}}{\Pi_{m, t}}-1\right) \frac{\Pi_{m, t+1}}{\Pi_{m, t}}\right) \Gamma_{m, t+1} \widetilde{Y}_{m, t+1}\right] \\
& +\beta^{2} E_{t}\left[\frac{\widetilde{\Lambda}_{c, t+2}}{\widetilde{\Lambda}_{c, t+1}} \frac{\widetilde{\Lambda}_{c, t+1}}{\widetilde{\Lambda}_{c, t}} \frac{\Pi_{m, t+1}}{\Pi_{c, t+1}} \frac{\Pi_{m, t+2}}{\Pi_{c, t+2}}\left(\Gamma_{c, t+2} \Gamma_{c, t+1}\right)^{-\sigma}\left(\chi_{p, 2}\left(\frac{\Pi_{m, t+2}}{\Pi_{m, t+1}}-1\right) \frac{\Pi_{m, t+2}}{\Pi_{m, t+1}}\right) \Gamma_{m, t+1} \Gamma_{m, t+1} \widetilde{Y}_{m, t+2}\right] .
\end{aligned}
$$

\section{Stationary and Symmetric Steady-state Equilibrium}

The steady-state growth rates in the materials, capital, and consumption goods sectors are given by

$$
\Gamma_{m}=\Gamma_{a, m} \Gamma_{a, i}^{\alpha}, \quad \Gamma_{i}=\Gamma_{a, m} \Gamma_{a, i}, \quad \text { and } \quad \Gamma_{c}=\Gamma_{a, m} \Gamma_{a, i}^{\alpha} \Gamma_{a, c}^{1-\alpha}
$$

where the calibrated values of the growth rates $\Gamma_{a, m}, \Gamma_{a, i}$, and $\Gamma_{a, c}$ are given in section 4 . The steady-state inflation rates of consumption and capital prices and of nominal wages are given by:

$$
\Pi_{c}=\Pi_{m} \Gamma_{a, c}^{-(1-\alpha)}, \quad \Pi_{i}=\Pi_{m} \Gamma_{a, i}^{-(1-\alpha)}, \quad \text { and } \quad \Pi_{w}=\Pi_{m} \Gamma_{a, m} \Gamma_{a, i}^{\alpha} .
$$

The nominal interest rate is given by:

$$
R=\frac{1}{\beta} \Gamma_{c}^{\sigma} \Pi_{c}
$$

while the real interest rates relevant to consumers, capitalists, and material good producers respectively are:

$$
\frac{R}{\Pi_{c}}=\frac{1}{\beta} \Gamma_{c}^{\sigma}, \quad \frac{R}{\Pi_{i}}=\frac{1}{\beta} \Gamma_{c}^{\sigma} \frac{\Pi_{c}}{\Pi_{i}}, \quad \text { and } \quad \frac{R}{\Pi_{m}}=\frac{1}{\beta} \Gamma_{c}^{\sigma} \frac{\Pi_{c}}{\Pi_{m}}
$$

The steady-state values of the relative prices of consumption, and uninstalled and installed capital goods (that is, $\widetilde{P}_{c, t}, \widetilde{P}_{i, t}$, and $\widetilde{Q}_{t}$ ) are unity. The steady-state values of real marginal cost, the real rental rate, and the real wage are:

$$
\begin{aligned}
\widetilde{M C}_{m} & =\frac{\theta-1}{\theta} \\
\widetilde{R}_{k} & =\frac{1}{\beta} \Gamma_{c}^{\sigma} \frac{\Pi_{c}}{\Pi_{i}}-(1-\delta)=\frac{R}{\Pi_{i}}-(1-\delta) \\
\widetilde{W} & =(1-\alpha)\left(\frac{\theta-1}{\theta}\right)^{\frac{1}{1-\alpha}}\left(\frac{\alpha}{\frac{R}{\Pi_{i}}-(1-\delta)}\right)^{\frac{\alpha}{1-\alpha}}
\end{aligned}
$$

The steady-state ratios $\frac{L}{\widetilde{Y}_{m}}, \frac{\widetilde{K}}{\widetilde{Y}_{m}}, \frac{\widetilde{I}}{\widetilde{Y}_{m}}=\frac{\widetilde{Y}_{i}}{\widetilde{Y}_{m}}$, and $\frac{\widetilde{C}}{\widetilde{Y}_{m}}=\frac{\widetilde{Y}_{c}}{\widetilde{Y}_{m}}$ :

$$
\frac{L}{\widetilde{Y}_{m}}=\left(\frac{1-\alpha}{\alpha}\right)^{\alpha}\left(\frac{\widetilde{R}_{k}}{\widetilde{W}}\right)^{\alpha}
$$




$$
\begin{aligned}
& \frac{\widetilde{K}}{\widetilde{Y}_{m}}=\left(\frac{\alpha}{1-\alpha}\right)^{1-\alpha}\left(\frac{\widetilde{W}}{\widetilde{R}_{k}}\right)^{1-\alpha} \\
& \frac{\widetilde{I}}{\widetilde{Y}_{m}}=\frac{\widetilde{Y}_{k}}{\widetilde{Y}_{m}}=\left(\Gamma_{i}-(1-\delta)\right)\left(\frac{\alpha}{1-\alpha}\right)^{1-\alpha}\left(\frac{\widetilde{W}}{\widetilde{R}_{k}}\right)^{1-\alpha} \\
& \frac{\widetilde{C}}{\widetilde{Y}_{m}}=\frac{\widetilde{Y}_{c}}{\widetilde{Y}_{m}}=1-\left(\Gamma_{i}-(1-\delta)\right)\left(\frac{\alpha}{1-\alpha}\right)^{1-\alpha}\left(\frac{\widetilde{W}}{\widetilde{R}_{k}}\right)^{1-\alpha}
\end{aligned}
$$

The steady-state solution for materials output is:

$$
\widetilde{Y}_{m}=\bar{L}\left(\frac{L}{\widetilde{Y}_{m}}+\frac{\zeta}{1-\eta \Pi_{c} / R} \cdot \frac{\widetilde{C}}{\widetilde{M}} \cdot \frac{1-\frac{\eta}{\Gamma_{c}}}{\widetilde{W}} \cdot \frac{\rho}{\rho-1}\right)^{-1}
$$

\section{Log-Linearized First-order Conditions}

The log-linearized versions of the final-good producing firms' first-order conditions are:

$$
p_{c, t}=0 \quad \text { and } \quad p_{k, t}=0 .
$$

The demand function from the symmetric equilibrium is

$$
y_{m, t}=\frac{\tilde{Y}_{c}}{\widetilde{Y}_{c}+\widetilde{Y}_{i}} y_{c, t}+\frac{\tilde{Y}_{i}}{\widetilde{Y}_{c}+\widetilde{Y}_{i}} y_{i, t}
$$

where it can be shown that $\frac{\widetilde{Y}_{c}}{\widetilde{Y}_{c}+\widetilde{Y}_{i}}$ and $\frac{\widetilde{Y}_{i}}{\widetilde{Y}_{c}+\widetilde{Y}_{i}}$ are equal to the steady-state nominal shares of consumption and capital goods output in total final goods output respectively. Market clearing in the final goods markets imply that $y_{c, t}=c_{t}$ and $y_{i, t}=i_{t}$, together with the equations in (77), allows us to write equation (78) more as a market clearing condition for the materials sector, that is,

$$
y_{m, t}=\frac{\widetilde{Y}_{c}}{\widetilde{Y}_{c}+\widetilde{Y}_{i}} c_{t}+\frac{\tilde{Y}_{i}}{\widetilde{Y}_{c}+\widetilde{Y}_{i}} i_{t}
$$

The log-linearized versions of the capitalists first-order conditions (53) and (54) are:

$$
\begin{gathered}
\left(i_{t}+\gamma_{i, t}\right)+\frac{\Gamma_{i} \Pi_{i}}{R} i_{t}=i_{t-1}+\frac{\Gamma_{i} \Pi_{i}}{R}\left(E_{t} i_{t+1}+E_{t} \gamma_{i, t+1}\right)+\frac{1}{\chi_{i} \Gamma_{i}}\left(q_{k, t}-p_{i, t}\right) \\
E_{t} r_{k, t+1}-E_{t} p_{i, t+1}=\frac{R / \Pi_{i}}{R / \Pi_{i}-(1-\delta)}\left(r_{t}-E_{t} \pi_{i, t+1}+q_{k, t}-p_{i, t}\right)-\frac{(1-\delta)}{R / \Pi_{i}-(1-\delta)}\left(E_{t} q_{k, t+1}-E_{t} p_{i, t+1}\right)
\end{gathered}
$$

The log-linearized version of the capital evolution equation is:

$$
k_{t}=\left(\frac{1-\delta}{\Gamma_{i}}\right) k_{t-1}+\left(\frac{\Gamma_{i}-1+\delta}{\Gamma_{i}}\right) i_{t-1}-\gamma_{i, t}
$$


The log-linearized versions of the household's Euler equation (equation 56) and labor supply curve (equation 57) are:

$$
\lambda_{c, t}=r_{t}-E_{t} \pi_{c, t+1}-\sigma E_{t} \gamma_{c, t+1}+E_{t} \lambda_{c, t+1}
$$

and

$$
\begin{aligned}
\left(\chi_{w, 1} \Pi_{w}{ }^{2}+\chi_{w, 2}\left(1+2 \frac{\Gamma_{c} \Pi_{c}}{R}\right)\right) \pi_{w, t} & =\chi_{w, 2} \pi_{w, t-1}+\left(\frac{\Gamma_{c} \Pi_{c}}{R}\right)\left(\chi_{w, 1} \Pi_{w}{ }^{2}+\chi_{w, 2}\left(2+\frac{\Gamma_{c} \Pi_{c}}{R}\right)\right) E_{t} \pi_{w, t+1} \\
& -\left(\frac{\Gamma_{c} \Pi_{c}}{R}\right)^{2} \chi_{w, 2} E_{t} \pi_{w, t+2}+\frac{\widetilde{W} L}{\widetilde{P}_{c} \widetilde{C}}(\rho-1)\left(\lambda_{l, t}-\lambda_{c, t}-\left(w_{t}-p_{c, t}\right)\right)
\end{aligned}
$$

where:

$$
\begin{aligned}
\lambda_{c, t} & =\frac{1}{1-\eta \Gamma_{c} \Pi_{c} / R}\left(\frac{-\sigma}{1-\eta}\left(c_{t}-\eta c_{t-1}+\eta \gamma_{c, t}\right)-\zeta(1-\sigma) \frac{L}{\bar{L}-L} l_{t}\right) \\
& -\frac{\eta \Gamma_{c} \Pi_{c} / R}{1-\eta \Gamma_{c} \Pi_{c} / R}\left(\frac{-\sigma}{1-\eta}\left(E_{t} c_{t+1}-\eta c_{t}+\eta E_{t} \gamma_{c, t+1}\right)-\zeta(1-\sigma) \frac{L}{\bar{L}-L} E_{t} l_{t+1}-\sigma E_{t} \gamma_{c, t+1}\right)(85)
\end{aligned}
$$

and

$$
\lambda_{l, t}=\frac{1-\sigma}{1-\eta}\left(c_{t}-\eta c_{t-1}+\eta \gamma_{c, t}\right)+(1-\zeta(1-\sigma))\left(\frac{L}{\bar{L}-L}\right) l_{t}
$$

The material producing firms' first-order conditions (equations to 60 to 64 ) can be loglinearized and rearranged to yield labor and capital demand functions, as well as an equation for the degree of utilization and an expression for marginal cost:

$$
\begin{aligned}
l_{t} & =y_{m, t}-\alpha\left(1+\frac{1-\alpha}{\Psi^{\prime \prime}(1) / \Psi^{\prime}(1)}\right)\left(w_{t}-r_{k, t}\right), \\
k_{t} & =y_{m, t}+(1-\alpha)\left(1+\frac{1-\alpha}{\Psi^{\prime \prime}(1) / \Psi^{\prime}(1)}\right)\left(w_{t}-r_{k, t}\right), \\
u_{t} & =\frac{1-\alpha}{\Psi^{\prime \prime}(1) / \Psi^{\prime}(1)}\left(w_{t}-r_{k, t}\right), \\
m c_{m, t} & =(1-\alpha) w_{t}+\alpha r_{k, t}
\end{aligned}
$$

and

$$
\begin{aligned}
\left(\chi_{p, 1} \Pi_{m}{ }^{2}+\chi_{p, 2}\left(1+2 \frac{\Gamma_{m} \Pi_{m}}{R}\right)\right) \pi_{m, t} & =\chi_{p, 2} \pi_{m, t-1}+\frac{\Gamma_{m} \Pi_{m}}{R}\left(\chi_{p, 1} \Pi_{m}{ }^{2}+\chi_{p, 2}\left(2+\frac{\Gamma_{m} \Pi_{m}}{R}\right)\right) E_{t} \pi_{m, t+1} \\
& -\left(\frac{\Gamma_{m} \Pi_{m}}{R}\right)^{2} \chi_{p, 2} E_{t} \pi_{m, t+2}+(\theta-1) m c_{m, t}
\end{aligned}
$$

The log-linearized first-order conditions for the inflation rates of wages and materials prices imply the following evolution for real wages:

$$
E_{t} w_{t+1}-w_{t}+E_{t} \gamma_{a, m, t+1}+E_{t} \alpha \gamma_{a, i, t+1}=E_{t} \pi_{w, t+1}-E_{t} \pi_{m, t+1}
$$


while the expected inflation rates for the consumption and capital good prices are given by:

$$
\begin{aligned}
& E_{t} \pi_{c, t+1}=E_{t} \pi_{m, t+1}-(1-\alpha) E_{t} \gamma_{c, t+1} \\
& E_{t} \pi_{i, t+1}=E_{t} \pi_{m, t+1}-(1-\alpha) E_{t} \gamma_{i, t+1} .
\end{aligned}
$$

It is worth emphasizing, to avoid confusion, that $\pi_{c, t}$ and $\pi_{i, t}$ represent the change in the level of consumption and capital goods prices and not the change in the relative prices of consumption and capital goods. Specifically, $\pi_{c, t} \neq p_{c, t}-p_{c, t-1}$ and $\pi_{i, t} \neq p_{i, t}-p_{i, t-1}$. In the flexible wage and price version of our model equations (92), (93), and (94) are given by

$$
\begin{aligned}
E_{t} \pi_{w, t+1} & =E_{t} w_{t+1}-w_{t}+E_{t} \gamma_{a, m, t+1}+E_{t} \alpha \gamma_{a, i, t+1} \\
E_{t} \pi_{c, t+1} & =-(1-\alpha) E_{t} \gamma_{c, t+1} \\
E_{t} \pi_{i, t+1} & =-(1-\alpha) E_{t} \gamma_{i, t+1}
\end{aligned}
$$

Finally, the deviations from steady-state of the growth rates of $A_{c, t}$ and $A_{i, t}$,

$$
\begin{aligned}
& \gamma_{c, t}=\gamma_{a, m, t}+\alpha \gamma_{a, i, t}+(1-\alpha) \gamma_{a, c, t} \\
& \gamma_{i, t}=\gamma_{a, m, t}+\gamma_{a, i, t}
\end{aligned}
$$

For almost all variables in the model the title assigned to them it very similar to that variable's empirical concept. One exception is the variable $Q_{k, t}$ in the model, which is the installed price of capital, rather than the ratio of the price of installed to uninstalled capital. For this we introduce a variable $Q_{t}^{\text {tobin }}$ defined at $\frac{Q_{k, t}}{P_{i, t}}$ so that in our log-linearized equations it is the term $q_{k, t}-p_{i, t}=q_{t}^{\text {tobin }}$ that is the log-deviation of Tobin's $q$ from its steady-state value of unity. 